\title{
State-of-the-Art Review of $\mathrm{CO}_{2}$ Demand Controlled Ventilation Technology and Application
}

Steven J. Emmerich

Andrew K. Persily

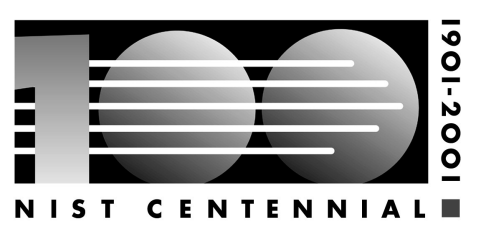

National Institute of Standards and Technology Technology Administration, U.S. Department of Commerce 


\section{State-of-the-Art Review of $\mathrm{CO}_{2}$ Demand Controlled Ventilation Technology and Application}

Steven J. Emmerich

Andrew K. Persily

Building and Fire Research Laboratory

Prepared for: Architectural Energy Corporation

Boulder, Colorado

March 2001

$\underline{\text { U.S. Department of Commerce }}$

Donald L. Evans, Secretary

National Institute of Standards and Technology

Karen H. Brown, Acting Director

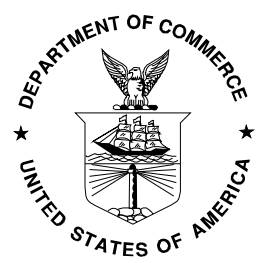




\begin{abstract}
The control of outdoor air intake rates in mechanically ventilated buildings based on indoor carbon dioxide $\left(\mathrm{CO}_{2}\right)$ levels, often referred to as $\mathrm{CO}_{2}$ demand controlled ventilation (DCV), has the potential for reducing the energy consumption associated with building ventilation in some commercial and institutional buildings. Carbon dioxide DCV has been discussed, promoted, studied and demonstrated for about twenty years, but questions still remain regarding the actual energy savings potential as a function of climate, ventilation system features, and building occupancy. In addition, questions exist as to the indoor air quality (IAQ) impacts of the approach and the best way to implement $\mathrm{CO}_{2} \mathrm{DCV}$ in general and in a given building. This report presents a state-of-the-art review of $\mathrm{CO}_{2} \mathrm{DCV}$ technology and application including discussion of the concept and its application, and a literature review. In addition the regulatory and standard requirements impacting $\mathrm{CO}_{2} \mathrm{DCV}$ are also examined.
\end{abstract}

Keywords: carbon dioxide, control, energy efficiency, indoor air quality, ventilation 


\section{TABLE OF CONTENTS}

Abstract

1. INTRODUCTION

2. TECHNICAL BACKGROUND: CARBON DIOXIDE IN BUILDINGS

2.1 Carbon Dioxide Generation Rates 2

2.2 Carbon Dioxide, Indoor Air Quality and Ventilation 4

3. LITERATURE REVIEW 11

3.1 Case Studies - Field Tests 11

3.2 Case Studies - Simulations 14

3.3 Sensor Performance and Location 20

3.4 Application 23

3.5 Summary and Conclusions 25

4. TECHNOLOGY UPDATE: SENSORS 28

5. STANDARDS AND REGULATORY CONTEXT 29

6. SUMMARY 31

7. ACKNOWLEDGEMENTS 32

8. REFERENCES 33

Appendix A: CEC RFP Issues 39

Appendix B: Preliminary Application Guidance and Issues 41

THIS REPORT WAS PREPARED AS A RESUlT OF WORK SPONSORED BY THE CALIFORNia ENERgY COMMISSION (COMMISSION). IT DOES NOT NECESSARILY REPRESENT THE VIEWS OF THE COMMISSION, ITS EMPLOYEES, OR THE STATE OF California. The Commission, the State of California, its employees, CONTRACTORS, AND SUBCONTRACTORS MAKE NO WARRANTY, EXPRESS OR IMPLIED, AND ASSUME NO LEGAL LIABILITY FOR THE INFORMATION IN THIS REPORT; NOR DOES ANY PARTY REPRESENT THAT THE USE OF THIS INFORMATION WILL NOT INFRINGE UPON PRIVATELY OWNED RIGHTS. THIS REPORT HAS NOT BEEN APPROVED OR DISAPPROVED BY THE COMMISSION NOR HAS THE COMMISSION PASSED UPON THE ACCURACY OR ADEQUACY OF THE INFORMATION IN THIS REPORT. 


\section{INTRODUCTION}

Many ventilation requirements and recommendations, e.g., ASHRAE Standard 62-1999, are in the form of outdoor airflow rates per person expressed as L/s or $\mathrm{cfm}$ per person. Mechanical ventilation systems are therefore designed to provide a minimum level of outdoor air based on the designed occupancy level multiplied by the per-person ventilation requirement. However, a space that is occupied at less than its design level may still be ventilated at this design minimum rate, often resulting in increased energy consumption beyond that which would be required based on the actual occupancy. Furthermore, early during a given day of building occupancy, contaminants generated by people and their activities will not yet have reached their ultimate levels based on the transient nature of the situation. As a result, it is sometimes possible to delay or lag the onset of the design ventilation rate to take credit for this transient effect. A number of approaches have been proposed to account for actual occupancy levels and to provide the ventilation rate corresponding to the actual rather than design occupancy. These include timebased scheduling when the occupancy patterns are well known and predictable, occupancy sensors to determine when people have entered a space (though not necessarily how many) and $\mathrm{CO}_{2}$ sensing and control as a means of estimating the number of people in a space or at least the strength of occupant-related contaminant sources.

Controlling outdoor air intake rates using $\mathrm{CO}_{2}$ demand controlled ventilation (DCV) offers the possibility of reducing the energy penalty of over-ventilation during periods of low occupancy, while still ensuring adequate levels of outdoor air ventilation. As discussed later in this report, depending on climate and occupancy patterns, $\mathrm{CO}_{2} \mathrm{DCV}$ may provide significant energy savings in commercial and institutional buildings. While a number of studies have suggested the extent of such savings via field studies and computer simulations, additional work is needed to better define the magnitude of energy savings possible and the dependence of these savings on climate, building and system type, control approach, and occupancy patterns. In addition, important issues remain to be resolved in the application of $\mathrm{CO}_{2} \mathrm{DCV}$ including how best to apply the control approach, including issues such as which control approach to use in a given building, sensor location, sensor maintenance and calibration, and the amount of baseline ventilation required to control contaminant sources that don't depend on the number of occupants.

This report presents a state-of-the-art review of $\mathrm{CO}_{2}$ DCV technology and its application in commercial and institutional buildings. Following this introduction, the next section presents the theoretical background of $\mathrm{CO}_{2} \mathrm{DCV}$ including discussions of $\mathrm{CO}_{2}$ generation rates by people, the relationship of indoor $\mathrm{CO}_{2}$ to building ventilation rates, and the basic concept of controlling ventilation based on indoor $\mathrm{CO}_{2}$ levels. The third section of the report is a literature review of previous research on $\mathrm{CO}_{2} \mathrm{DCV}$, including field demonstration projects, computer simulation studies, studies of sensor performance and location, and discussions of the application of the approach. The next section of the report contains an update on $\mathrm{CO}_{2}$ sensor technology as it applies to DCV. The manner in which $\mathrm{CO}_{2} \mathrm{DCV}$ is addressed in standards and other regulations, including California's Energy Efficiency Standards (often referred to as Title 24), is presented in section five of this report. The report also contains two appendices. The first appendix discusses how $\mathrm{CO}_{2} \mathrm{DCV}$ relates to the four issues identified by the California Energy Commission Public Interest Energy Research Request for Proposal \#400-99-401 that resulted in this project. The second appendix summarizes preliminary guidance on the application of $\mathrm{CO}_{2}$ DCV based on the material reviewed in preparing this report. While future phases of this effort are intended to develop more definitive guidance, this appendix attempts to capture some of the guidance that has been developed to date while identifying some issues that remain to be resolved. 


\section{TECHNICAL BACKGROUND: CARBON DIOXIDE IN BUILDINGS}

In order to evaluate the possibilities and application of $\mathrm{CO}_{2} \mathrm{DCV}$, it is important to understand the dynamics of indoor $\mathrm{CO}_{2}$. This section discusses these dynamics, including indoor $\mathrm{CO}_{2}$ generation rates, how indoor $\mathrm{CO}_{2}$ levels relate to ventilation, and how $\mathrm{CO}_{2}$ can be used to control ventilation. Much of this material is based on an earlier publication by Persily (1997). This discussion does not cover the issue of using indoor $\mathrm{CO}_{2}$ to measure or estimate building ventilation rates, but rather is focused on issues related to ventilation rate control based on indoor $\mathrm{CO}_{2}$ levels. Persily (1997) contains a discussion of the measurement issue, as does ASTM Standard D6245 (1998).

\subsection{Carbon Dioxide Generation Rates}

While it is not critical to the application of $\mathrm{CO}_{2} \mathrm{DCV}$, the emission rate of occupant generated $\mathrm{CO}_{2}$ is certainly a relevant issue in this discussion. This section discusses the rate at which people generate $\mathrm{CO}_{2}$.

People generate $\mathrm{CO}_{2}$, and consume oxygen, at a rate that depends primarily on their body size and their level of physical activity. The relationship between activity level and the rates of carbon dioxide generation and oxygen consumption is discussed in the ASHRAE Fundamentals Handbook (ASHRAE 1997). The rate of oxygen consumption $\mathrm{V}_{\mathrm{O} 2}$, in $\mathrm{L} / \mathrm{s}$, of a person is given by the following equation

$$
V_{O 2}=\frac{0.00276 A_{D} M}{(0.23 R Q+0.77)}
$$

When using inch-pound units, $\mathrm{V}_{\mathrm{O} 2}$ is expressed in cfm and Equation (1) takes the form

$$
V_{O 2}=\frac{0.000543 A_{D} M}{(0.23 R Q+0.77)}
$$

where RQ is the respiratory quotient, i.e., the relative volumetric rates of carbon dioxide produced to oxygen consumed. $\mathrm{M}$ is the level of physical activity, or the metabolic rate per unit of surface area, in mets $\left(1 \mathrm{met}=58.2 \mathrm{~W} / \mathrm{m}^{2}=18.5 \mathrm{Btu} / \mathrm{h} \cdot \mathrm{ft}^{2}\right) . \mathrm{A}_{\mathrm{D}}$ is the DuBois surface area in $\mathrm{m}^{2}$, which can be estimated by the following equation

$$
A_{D}=0.203 H^{0.725} W^{0.425}
$$

where $\mathrm{H}$ is the body height in $\mathrm{m}$ and $\mathrm{W}$ is the body mass in $\mathrm{kg}$. When using inch-pound units, $\mathrm{A}_{\mathrm{D}}$ is in $\mathrm{ft}^{2}, 0.203$ is replaced with $0.660, \mathrm{H}$ is in $\mathrm{ft}$ and $\mathrm{W}$ is in $\mathrm{lb}$. For an average size adult, $\mathrm{A}_{\mathrm{D}}$ equals about $1.8 \mathrm{~m}^{2}\left(19 \mathrm{ft}^{2}\right)$. Additional information on body surface area is available in the EPA Exposure Factors Handbook (EPA 1999). The value of RQ depends on diet, the level of physical activity and the physical condition of the person. It is equal to 0.83 for an average size adult engaged in light or sedentary activities. RQ increases to a value of about 1 for heavy physical activity, about 5 met. Given the expected range of RQ, it has only a secondary effect on carbon dioxide generation rates.

The carbon dioxide generation rate of an individual is therefore equal to $\mathrm{V}_{\mathrm{O} 2}$ multiplied by $\mathrm{RQ}$. Figure 1 shows oxygen consumption and carbon dioxide generation rates as a function of physical activity for an average sized adult with a surface area of $1.8 \mathrm{~m}^{2}\left(19 \mathrm{ft}^{2}\right)$ and $\mathrm{RQ}=0.83$. Based on Equation 1, the carbon dioxide generation rate corresponding to an average size adult engaged in office work $(1.2 \mathrm{met})$ is about $0.0052 \mathrm{~L} / \mathrm{s}(0.011 \mathrm{cfm})$. However, the generation rate depends strongly on activity level and can cover a range from less than $0.0050 \mathrm{~L} / \mathrm{s}(0.011 \mathrm{cfm})$ at 1 met to as high as $0.010 \mathrm{~L} / \mathrm{s}(0.021 \mathrm{cfm})$ at about 2 met for the occupants of an office building. 
The carbon dioxide generation rate for a child with $A_{D}=1 \mathrm{~m}^{2}\left(11 \mathrm{ft}^{2}\right)$ and a physical activity level of $1.2 \mathrm{met}$ is equal to $0.0029 \mathrm{~L} / \mathrm{s}(0.0061 \mathrm{cfm})$. When making calculations that use the carbon dioxide generation rate in a building, one must consider the level of physical activity and the size of the building occupants. Chapter 8 of the ASHRAE Fundamentals Handbook, Thermal Comfort, (ASHRAE 1997) contains typical met levels for a variety of activities. Some of these values are reproduced in Table 1.

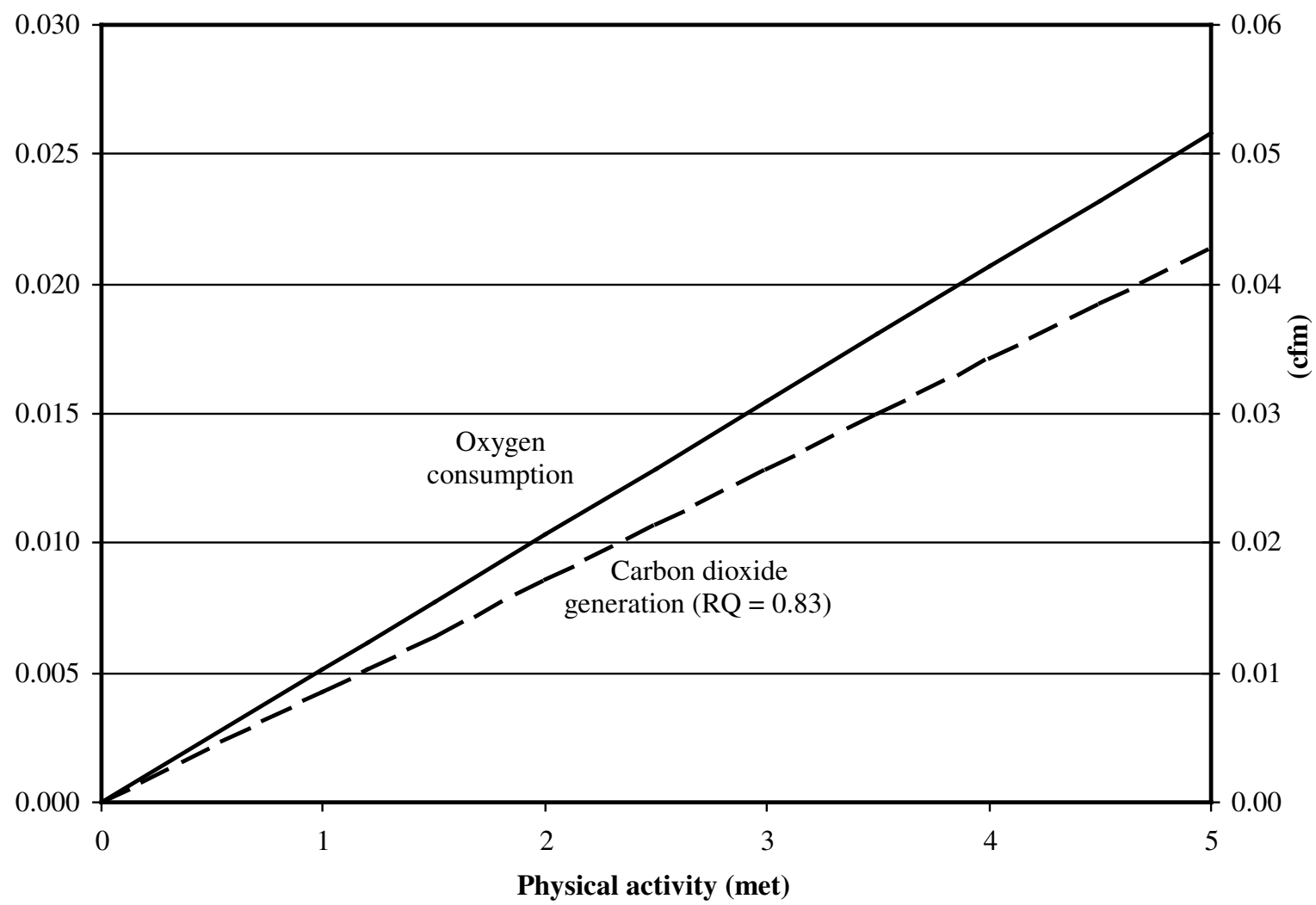

Figure $1 \mathrm{CO}_{2}$ generation and $\mathrm{O}_{2}$ consumption as a function of physical activity (for an average size adult)

Oxygen depletion is sometimes cited as a cause of indoor air quality complaints in buildings. Based on the oxygen consumption rates determined with Equation $1, \mathrm{O}_{2}$ depletion due to low ventilation rates is almost never an issue. Given an activity level corresponding to office work, about 1.2 met, the oxygen consumption rate of an individual equals $0.006 \mathrm{~L} / \mathrm{s}(0.013 \mathrm{cfm})$. At an outdoor air ventilation rate of $7.5 \mathrm{~L} / \mathrm{s}(16 \mathrm{cfm})$ per person, the steady-state indoor oxygen concentration is reduced from its typical outdoor level of $21 \%$ to $20.9 \%$. At $2.5 \mathrm{~L} / \mathrm{s}(5.3 \mathrm{cfm})$, the indoor oxygen concentration is reduced to $20.8 \%$. Reduced oxygen concentrations do not affect human health or comfort until oxygen levels decrease below $19.5 \%$ (NIOSH 1987), which corresponds to an outdoor air ventilation rate of $0.4 \mathrm{~L} / \mathrm{s}(0.8 \mathrm{cfm})$ per person. Such low oxygen concentrations are not typically encountered indoors, except in confined spaces where another gas is displacing oxygen or during fires. 


\begin{tabular}{|l|c|}
\hline \multicolumn{1}{|c|}{ Activity } & Met \\
\hline Seated, quiet & 1.0 \\
\hline Reading and writing, seated & 1.0 \\
\hline Typing & 1.1 \\
\hline Filing, seated & 1.2 \\
\hline Filing, standing & 1.4 \\
\hline Walking at $0.9 \mathrm{~m} / \mathrm{s}(2 \mathrm{mph})$ & 2.0 \\
\hline House cleaning & $2.0-3.4$ \\
\hline Exercise & $3.0-4.0$ \\
\hline
\end{tabular}

Table 1 Typical Met Levels for Various Activities (ASHRE 1997)

\subsection{Carbon Dioxide, Indoor Air Quality and Ventilation}

There has been a great deal of confusion over the years with respect to the relationship of indoor $\mathrm{CO}_{2}$ levels, indoor air quality and ventilation (Persily 1993 and 1997), much of which has carried over into the discussion of demand controlled ventilation. One of the primary issues has been the significance of indoor $\mathrm{CO}_{2}$ levels as an indicator of indoor air quality and the ability to maintain acceptable indoor air quality based on the control of indoor $\mathrm{CO}_{2}$ levels. This section discusses the significance of indoor $\mathrm{CO}_{2}$ levels in the context of indoor air quality and ventilation.

Indoor $\mathrm{CO}_{2}$ concentrations have been referred to as an indicator of indoor air quality, often without describing the specific association between carbon dioxide and indoor air quality that is being indicated. There are a number of relationships that could be implied in discussing carbon dioxide and indoor air quality including the relationship between carbon dioxide concentrations and occupant perceptions of the indoor environment, the relationship between carbon dioxide concentrations and the concentrations of other indoor contaminants, and the relationship between carbon dioxide and outdoor air ventilation rates. While some of these relationships are relatively well understood, and in some cases well founded, others have not been documented experimentally or theoretically. In other words, indoor carbon dioxide concentrations can be used to indicate specific and limited aspects of indoor air quality, but do not provide an overall indication of the quality of indoor air. However, this relationship is almost an entirely different issue from that of controlling outdoor air intake rates based on $\mathrm{CO}_{2}$ levels as discussed below.

\section{Carbon Dioxide and Indoor Air Quality}

Carbon dioxide is not generally considered to be a health concern at typical indoor concentrations. The time-weighted average threshold limit value ( $8 \mathrm{~h}$ exposure and a $40 \mathrm{~h}$ work week) for carbon dioxide is $9000 \mathrm{mg} / \mathrm{m}^{3}$ (5000 $\left.\mathrm{ppm}(\mathrm{v})\right)$, and the short-term exposure limit (15 min exposure) is $54000 \mathrm{mg} / \mathrm{m}^{3}$ (30 $000 \mathrm{ppm}(\mathrm{v})$ ) (ACGIH 2001). A number of studies at elevated concentrations, about $5 \%$ carbon dioxide in air or $90000 \mathrm{mg} / \mathrm{m}^{3}(50000 \mathrm{ppm}(\mathrm{v}))$, have been performed, and the lowest level at which effects have been seen in humans and animals is about $1 \%$, i.e., $18000 \mathrm{mg} / \mathrm{m}^{3}$ (10 000 ppm(v)) (EPA 1991). Indoor carbon dioxide concentrations will not reach these levels unless the ventilation rate is extremely low, about $1 \mathrm{~L} / \mathrm{s}$ ( $2 \mathrm{cfm})$ per person for $9000 \mathrm{mg} / \mathrm{m}^{3}(5000 \mathrm{ppm}(\mathrm{v}))$ and less than about $0.2 \mathrm{~L} / \mathrm{s}(0.4 \mathrm{cfm})$ per person for $54000 \mathrm{mg} / \mathrm{m}^{3}$ (30 $\left.000 \mathrm{ppm}(\mathrm{v})\right)$.

The association between carbon dioxide concentrations and occupant perceptions of the indoor environment in terms of comfort and irritation is complex because it mixes several different issues, including the comfort impacts of the carbon dioxide itself, associations between carbon 
dioxide levels and the concentrations of other occupant-generated contaminants, and the relationship between carbon dioxide and ventilation. Some indoor air quality investigators associate indoor carbon dioxide concentrations from $1100 \mathrm{mg} / \mathrm{m}^{3}(600 \mathrm{ppm}(\mathrm{v}))$ to $1800 \mathrm{mg} / \mathrm{m}^{3}$ $(1000 \mathrm{ppm}(\mathrm{v}))$ or higher with perceptions of stuffiness and other indicators of discomfort and irritation (Bright et al. 1992; Rajhans 1983; Bell and Khati 1983). However, these associations are often based on anecdotal observations of the investigator or on informal occupant surveys. Seppanen et al. (1999) reviewed twenty-one studies, involving more than thirty thousand subjects, of ventilation rates, indoor $\mathrm{CO}_{2}$ levels and sick building syndrome (SBS) symptoms and found that higher $\mathrm{CO}_{2}$ levels were associated with increased symptoms in about half of the studies. The authors do note that there were significant variations among the studies in the $\mathrm{CO}_{2}$ metric employed and a number of measurement issues. Also, they note that it is unlikely that the symptoms were associated with exposure to $\mathrm{CO}_{2}$, but rather to other contaminants. Apte et al. (2000) examined data from forty-one U.S. office buildings from the EPA BASE study in which the measurement protocol was standardized and probability sampling was used to select the buildings. Significant associations were seen between some SBS symptoms and $\mathrm{CO}_{2}$ levels, though the authors acknowledge that $\mathrm{CO}_{2}$ is likely a surrogate for other occupant-generated pollutants and for the ventilation rate per occupant. In other words, $\mathrm{CO}_{2}$ levels increase with increased occupancy and decreased ventilation rate, and it may be these latter two factors that are actually causing the symptoms. In addition, the observed associations between carbon dioxide and occupant comfort may be due to other factors, such as thermal comfort or the concentrations of other contaminants in the space. However, as discussed below, there is a demonstrated correlation between indoor carbon dioxide concentrations and the level of acceptability of the space in terms of human body odor.

The relationship between carbon dioxide concentrations and the concentrations of other indoor contaminants depends on the characteristics of the sources of these other contaminants. As discussed earlier, the rate at which carbon dioxide is generated in a space depends on the number of people in the space, their size and their level of physical activity. If other contaminants are generated at a rate that also depends on these factors, then carbon dioxide may be a good indicator of their concentrations. However, only some indoor contaminants are generated at a rate that depends on occupancy, and many are not a function of occupancy at all. For example, emissions from building materials and furnishings, the intake of outdoor contaminants by the ventilation system, and contaminants associated with some occupant activities do not depend on the number of occupants in a space. Regardless of the indoor carbon dioxide level, the concentration of contaminants emitted by occupant-independent sources may be high, low or in between and the carbon dioxide concentration will not provide any information on their concentration. This fact is one limitation on the use of carbon dioxide based demand controlled ventilation.

\section{Carbon Dioxide Concentrations and Body Odor Acceptability}

At the same time people are generating $\mathrm{CO}_{2}$, they are also producing odor-causing bioeffluents. Similar to carbon dioxide generation, the rate of bioeffluent generation depends on the level of physical activity. Bioeffluent generation also depends on diet and on personal hygiene. Because both carbon dioxide and bioeffluent generation rates depend on physical activity, the concentrations of carbon dioxide and the odor intensity from human bioeffluents in a space exhibit a similar dependence on the number of occupants and the outdoor air ventilation rate.

Experimental studies have been conducted in chambers and in occupied spaces, in which people evaluated the acceptability of the air in terms of body odor (Berg-Munch et al. 1986; Cain et al. 
1983; Fanger and Berg-Munch 1983; Fanger 1988; Iwashita et al. 1990; Rasmussen et al. 1985). These experiments studied the relationship between outdoor air ventilation rates and odor acceptability, and are a major consideration in developing the ventilation rate recommendations in ventilation standards. Some of the experiments also studied the relationship between the acceptability of the air in the space in terms of odor and carbon dioxide concentrations.

These studies have concluded that about $7 \mathrm{~L} / \mathrm{s}(15 \mathrm{cfm})$ of outdoor air ventilation per person will control human body odor such that roughly $80 \%$ of unadapted persons (visitors) will find the odor at an acceptable level. The same level of odor acceptability was found to occur at carbon dioxide concentrations that are about $1250 \mathrm{mg} / \mathrm{m}^{3}(700 \mathrm{ppm}(\mathrm{v}))$ above the outdoor concentration, which at a typical outdoor level of $630 \mathrm{mg} / \mathrm{m}^{3}(350 \mathrm{ppm}(\mathrm{v}))$ yields an indoor carbon dioxide concentration of $1880 \mathrm{mg} / \mathrm{m}^{3}(1050 \mathrm{ppm}(\mathrm{v}))$. Based on these considerations, $1800 \mathrm{mg} / \mathrm{m}^{3}$ (1000 ppm(v)) carbon dioxide is a commonly discussed guideline value (ASHRAE 1989). The differential between indoor and outdoor levels of $1250 \mathrm{mg} / \mathrm{m}^{3}(700 \mathrm{ppm}(\mathrm{v}))$ is a measure of acceptability with respect to body odor, irrespective of the outdoor carbon dioxide concentration. Figure 2 shows the percent of unadapted persons (visitors) who are dissatisfied with the level of body odor in a space as a function of the carbon dioxide concentration above outdoors (CEC 1992). People adapt quickly to bioeffluents. For adapted persons (occupants), the ventilation rate per person to provide the same acceptance is approximately one third of the value for unadapted persons (visitors) and the corresponding carbon dioxide concentrations above outdoors are three times higher (Berg-Munch et al. 1986; Cain et al. 1983).

The relationship between percent dissatisfied and carbon dioxide concentrations for visitors shown in Figure 2 was seen experimentally (Berg-Munch et al. 1986; Fanger and Berg-Munch 1983; Rasmussen et al. 1985), and the correlation was not strongly dependent on the level of physical activity. In addition, the relationship did not require that the indoor carbon dioxide concentration be at equilibrium. The relationship described in Figure 2 can also be derived based on the experimentally-determined relationship between percent dissatisfied and outdoor air ventilation rates in L/s (cfm) and the relationship between outdoor air ventilation rates and equilibrium carbon dioxide concentrations that is described later in this paper. 


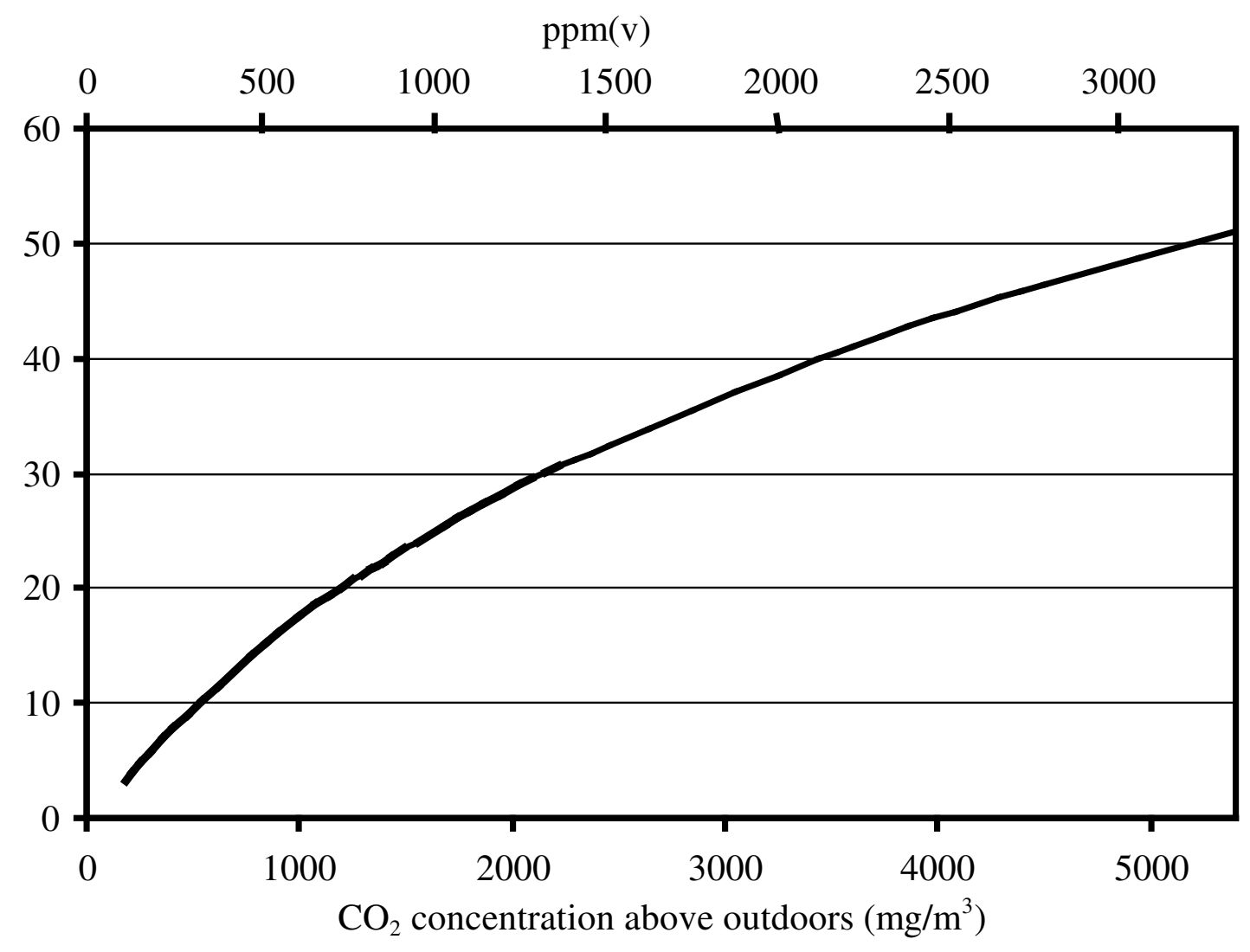

Figure 2 Percent of Visitors Dissatisfied with Bioeffluents Odor as a Function of $\mathrm{CO}_{2}$ Concentration (CEC 1992)

While carbon dioxide concentrations can be an appropriate means of characterizing the acceptability of a space in terms of body odor, as stated earlier, they do not provide information on the control of contaminants from other pollutant sources such as building materials, furnishings and occupant activities. And while maintaining carbon dioxide concentrations within $1250 \mathrm{mg} / \mathrm{m}^{3}$ (700 ppm(v)) of outdoors should provide acceptable perceived air quality in terms of human body odor, it does not necessarily imply adequate control of these other pollutant sources.

Some have viewed this relationship of $\mathrm{CO}_{2}$ with bioeffluents perception as a problem with $\mathrm{CO}_{2}$ DCV, reasoning one can only control the level of odor from bioeffluents with this approach. This conclusion is erroneous, since $\mathrm{CO}_{2}$ can also serve as an indicator of ventilation per person independent of the relationship seen in Figure 2. 


\section{Carbon Dioxide and Ventilation Rates}

The relationship between carbon dioxide and outdoor air ventilation rates is fairly well understood (Persily and Dols 1990; Persily 1997). All else being equal, if the ventilation rate in an occupied space decreases then the carbon dioxide concentration will increase. However, making quantitative estimates of building ventilation rates based on measured $\mathrm{CO}_{2}$ concentrations requires the use of a specific technique that is appropriate to the conditions that exist in the building, and is not always as simple as has sometimes been suggested (Persily 1997). Fortunately, the use of $\mathrm{CO}_{2}$ DCV does not rely on making estimates of building ventilation rates based on $\mathrm{CO}_{2}$ concentrations. In the context of this report, the relevant issues of the relationship between indoor $\mathrm{CO}_{2}$ levels and ventilation include steady-state $\mathrm{CO}_{2}$ concentrations at a constant air change rate and the time it takes to achieve steady-state conditions.

Steady-state $\mathrm{CO}_{2}$ concentrations can be determined for a given ventilation rate based on a singlezone mass balance analysis. Assuming that the $\mathrm{CO}_{2}$ concentration in the building or space of interest can be characterized by a single value $\mathrm{C}$, the mass balance of $\mathrm{CO}_{2}$ can be expressed as follows:

$$
V \frac{d C}{d t}=G+Q C_{o u t}-Q C
$$

where

$$
\begin{aligned}
& \mathrm{V}=\text { building or space volume (mass) in } \mathrm{m}^{3}(\mathrm{mg}) \\
& \mathrm{C}=\text { indoor } \mathrm{CO}_{2} \text { concentration in } \mathrm{mg} / \mathrm{m}^{3}(\mathrm{ppm}(\mathrm{v})) \\
& \mathrm{C}_{\text {out }}=\text { outdoor } \mathrm{CO}_{2} \text { concentration in } \mathrm{mg} / \mathrm{m}^{3}(\mathrm{ppm}(\mathrm{v})) \\
& \mathrm{t}=\text { time in } \mathrm{s} \\
& \mathrm{G}=\text { indoor } \mathrm{CO}_{2} \text { generation rate in } \mathrm{mg} / \mathrm{s}\left(\mathrm{m}^{3} / \mathrm{s}\right) \\
& \mathrm{Q}=\text { building or space ventilation rate in } \mathrm{mg} / \mathrm{s}\left(\mathrm{m}^{3} / \mathrm{s}\right)
\end{aligned}
$$

For a constant generation rate (occupancy level) and constant ventilation rate and outdoor concentration, the indoor concentration will eventually attain a steady state or equilibrium concentration $\mathrm{C}_{\mathrm{ss}}$ given by the following expression:

$$
C_{s s}=C_{\text {out }}+G / Q
$$

If the generation rate $\mathrm{G}$ and the ventilation rate $\mathrm{Q}$ are expressed in $\mathrm{L} / \mathrm{s}$ (as in Figure 1), and the concentrations are in $\mathrm{mg} / \mathrm{m}^{3}$, then Equation (5) takes the form:

$$
C_{s s}=C_{\text {out }}+\frac{1.8 \times 10^{6} G}{Q}
$$

If instead $\mathrm{G}$ and $\mathrm{Q}$ are expressed in $\mathrm{cfm}$ and the concentrations are in $\mathrm{ppm}(\mathrm{v})$, then Equation (5) takes the form:

$$
C_{s s}=C_{\text {out }}+\frac{10^{6} \times G}{Q}
$$

Therefore, as the ventilation rate increases, the steady-state $\mathrm{CO}_{2}$ concentration decreases. 
Assuming the building or space begins the day at the outdoor $\mathrm{CO}_{2}$ concentration and is then occupied, the indoor concentration will start to rise at a rate that depends on the building ventilation rate $\mathrm{Q}$ divided by the building volume $\mathrm{V}$. This quantity, $\mathrm{Q} / \mathrm{V}$, is sometimes referred to as the outdoor air change rate of the building, while its inverse V/Q is sometimes referred to as the time constant of the system. During this build-up, the indoor $\mathrm{CO}_{2}$ concentration is governed by the transient solution to Equation (4):

$$
C(t)=C_{\text {out }}+\frac{G}{Q}\left(1-e^{\frac{-Q t}{V}}\right)
$$

Note that as $\mathrm{t}$ approaches infinity, the concentration $\mathrm{C}$ approaches the steady-value given in Equation (5) as expected. It is also important to note that the time required to reach steady-state depends on the value of $\mathrm{Q} / \mathrm{V}$, with higher values (higher air change rates) corresponding to less time required to approach steady-state. Figure 3 is a plot of the build-up in indoor $\mathrm{CO}_{2}$ concentration, calculated from Equation (8), for different air change rates. Figure 3 is based on a generation rate of $0.0052 \mathrm{~L} / \mathrm{s}(0.011 \mathrm{cfm})$ per person and an outdoor concentration of $630 \mathrm{mg} / \mathrm{m}^{3}$ (350 $\mathrm{ppm}(\mathrm{v}))$

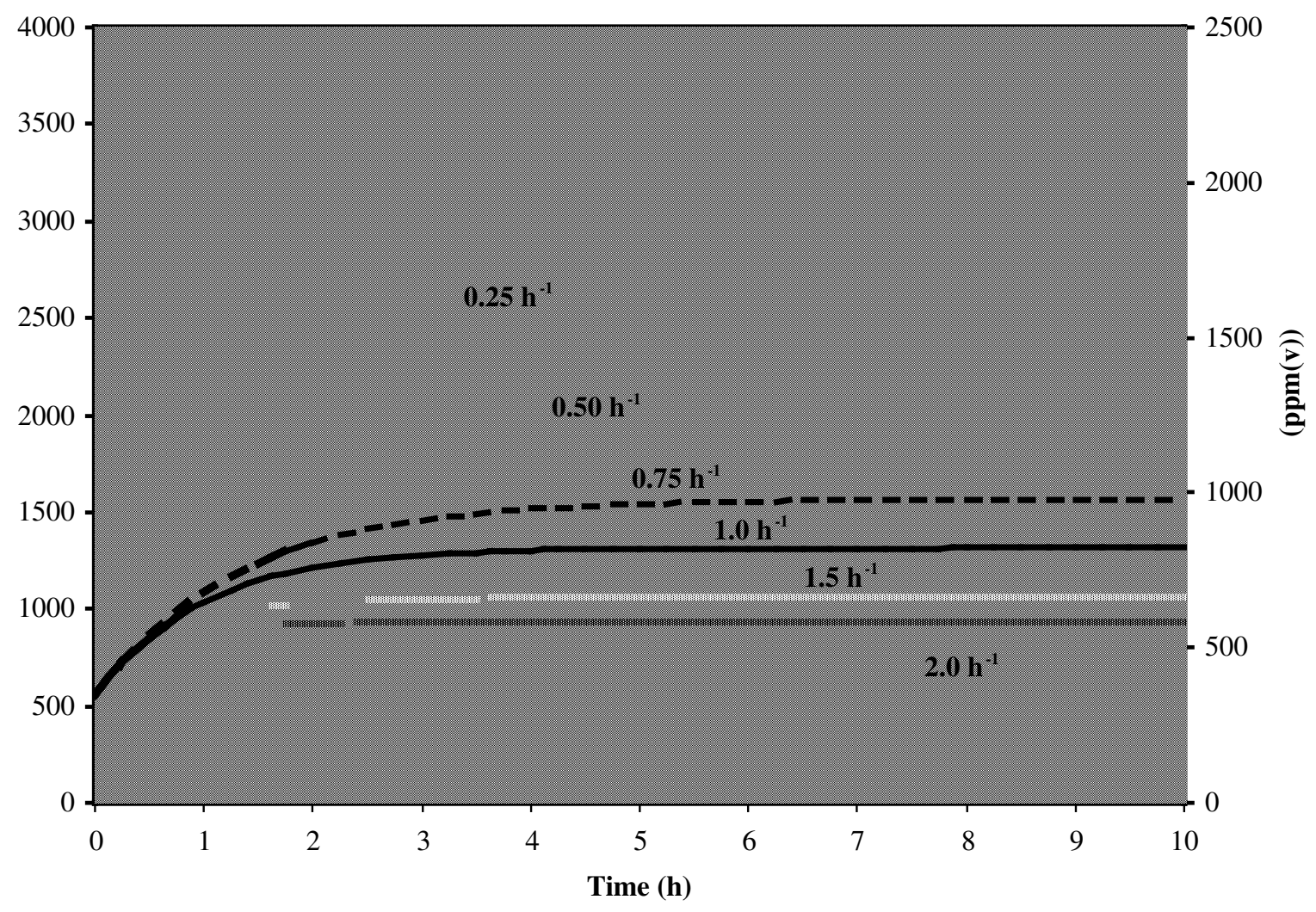

Figure 3 Calculated Carbon Dioxide Build-up as a Function of Air Change Rate

Figure 3 depicts the time required for indoor $\mathrm{CO}_{2}$ to reach steady-state concentration. Somehave identified this delay as a problem with the application of $\mathrm{CO}_{2}$ demand controlled ventilation. However, since DCV need not be based on the relationship between steady-state $\mathrm{CO}_{2}$ levels and ventilation rates, this buildup time is not a problem. 


\section{Carbon Dioxide Control versus Ventilation Control}

Some discussions, and criticisms, of $\mathrm{CO}_{2}$ demand controlled ventilation are based on the inadequacy of $\mathrm{CO}_{2}$ as an overall indicator of indoor air quality. This limitation has been noted above and is based on many important contaminants not being generated on a per-person basis, for example, building materials. However, the application of $\mathrm{CO}_{2} \mathrm{DCV}$ is better understood based on its use as an indicator of ventilation rate per person. Specifically, the control approach is more appropriately based on the desire to maintain a specific outdoor airflow rate per person based on a building code or ventilation standard. If the ventilation rate per person is lower than desired, the $\mathrm{CO}_{2}$ level will build up above its setpoint, or at a rate that is recognized as high, and the control system will need to respond by increasing the ventilation rate. If the ventilation rate is higher than required based on the design value of outdoor air per person, the $\mathrm{CO}_{2}$ level will be lower than the target and the control system can respond by decreasing the ventilation rate. That decrease is the mechanism by which $\mathrm{CO}_{2} \mathrm{DCV}$ realizes energy savings. However, the control system need not wait for the $\mathrm{CO}_{2}$ level to reach its steady-state value to make this decision. Control algorithms can be employed that anticipate where the $\mathrm{CO}_{2}$ level is headed and make adjustments to the ventilation rate well in advance of steady-state conditions. Furthermore, since other indoor contaminants buildup over time rather than instantaneously, $\mathrm{CO}_{2}$ control can be used to take advantage of this transient effect by lagging the start of ventilation for a period of time, thereby realizing additional energy savings. Therefore, it is important to realize that $\mathrm{CO}_{2}$ DCV uses indoor carbon dioxide to control ventilation and that the objective is not simply to control the indoor $\mathrm{CO}_{2}$ level. 


\section{LITERATURE REVIEW}

In the last fifteen years, interest in $\mathrm{CO}_{2}$-based DCV has led to a large body of literature published in journals, conference proceedings, and other forums. An extensive literature review (Raatschen 1990) covering all aspects of demand controlled ventilation, including non- $\mathrm{CO}_{2}$-based systems, was published at the conclusion of Annex 18, an International Energy Agency effort to develop guidelines for DCV systems. This supercedes a more limited review published during Annex 18 by Mansson (1989). The increasing interest in DCV in the U.S. is evidenced by recent articles published in several trade journals (Wright 1997; Di Giacomo 1999; Schell and Int-Hout 2001; and Schell 2001). The objective of this section, which is an update of an earlier report (Emmerich and Persily 1997), is to summarize the literature on $\mathrm{CO}_{2}$-based DCV as applied to non-residential buildings.

Literature reports on $\mathrm{CO}_{2}$-based DCV are categorized in this paper as follows: Case StudiesField Tests; Case Studies-Simulations; Sensor Performance and Location; and Application. The first two categories include studies of the performance of $\mathrm{CO}_{2}$-based DCV systems in real buildings and using computer models. The various case studies that have been conducted focus on issues including ventilation rates, energy consumption, economic impacts and the concentrations of other indoor pollutants, though few studies address all of these issues. The third category includes reports that address the performance of $\mathrm{CO}_{2}$ sensors and where they should be located in a space. The fourth category discusses the application of $\mathrm{CO}_{2}$-based DCV, from very general descriptions to detailed discussions of control algorithms.

\subsection{Case Studies-Field Tests}

There have been many demonstration projects in which $\mathrm{CO}_{2}$-based DCV systems were installed in buildings and some aspects of performance were monitored. These studies vary in many respects, including the detail with which the DCV systems are described. Some reports contain detailed descriptions of the DCV control algorithms, while others do not even report the setpoint. The studies also vary in the impacts that were monitored, which have included fan operation, damper position, indoor $\mathrm{CO}_{2}$ concentrations, ventilation rates, energy consumption, the concentrations of other pollutants, and occupant perceptions of the indoor environment. Finally, the studies have taken place in a variety of building types including offices, schools, auditoria and retail stores.

The application of $\mathrm{CO}_{2}$-based DCV is often discussed with reference to office buildings, and occasionally to conference rooms within office buildings. One of the earliest studies of $\mathrm{CO}_{2}$ control in an office building took place in Helsinki (Sodergren 1982). The outdoor air control algorithm is not described, but the $\mathrm{CO}_{2}$ setpoint was $1260 \mathrm{mg} / \mathrm{m}^{3}(700 \mathrm{ppm}(\mathrm{v}))$. The $\mathrm{CO}_{2}$ control system was compared to constant outdoor air and timer-based control, and 24-h plots of $\mathrm{CO}_{2}$ concentration are presented for each system. Measured concentrations of other pollutants and interviews with occupants did not indicate any IAQ problems.

Davidge (1991) presents a demonstration project in a 30,000 $\mathrm{m}^{2}\left(320,000 \mathrm{ft}^{2}\right)$ Canadian office building. In this building, the system never reduced the ventilation rate because the outdoor temperatures in the winter were never low enough to go off free-cooling. During the summer, damper leakage was more than enough to control $\mathrm{CO}_{2}$. Davidge also studied a boardroom, where supplemental ventilation was controlled alternatively by a light switch, a motion sensor and a $\mathrm{CO}_{2}$ controller. In the case of the $\mathrm{CO}_{2}$ controller, the fan came on at $1440 \mathrm{mg} / \mathrm{m}^{3}(800 \mathrm{ppm}(\mathrm{v}))$ and shut off at $1080 \mathrm{mg} / \mathrm{m}^{3}(600 \mathrm{ppm}(\mathrm{v}))$. An occupant questionnaire was administered, and it was found that the occupants could not distinguish whether or not the fan was on in terms of air 
quality. However, they rated the $\mathrm{CO}_{2}$ system very highly, presumably in terms of indoor air quality though the report does not specify the survey results in any detail.

A fairly comprehensive study of $\mathrm{CO}_{2}$ control took place on two floors of an office building in Montreal (Donnini et al. 1991, Haghighat and Donnini 1992). One floor was equipped with a $\mathrm{CO}_{2}$ DCV system, while the other floor served as a control. The $\mathrm{CO}_{2}$ control algorithm was as follows: the damper closed at concentrations below $1080 \mathrm{mg} / \mathrm{m}^{3}(600 \mathrm{ppm}(\mathrm{v}))$; as $\mathrm{CO}_{2}$ increased above $600 \mathrm{ppm}(\mathrm{v})$ the dampers opened with the maximum opening at $1800 \mathrm{mg} / \mathrm{m}^{3}$ $(1000 \mathrm{ppm}(\mathrm{v}))$. The study lasted one year, during which indoor concentrations of $\mathrm{CO}_{2}$, formaldehyde, volatile organic compounds and particles, ventilation system performance, thermal comfort, and occupant perception were measured once a month. Energy demand was monitored for the whole year. The outdoor air dampers were closed most of the year, because there were rarely enough people to raise the indoor $\mathrm{CO}_{2}$ concentration. The indoor air quality measurements revealed no significant contaminant concentration differences between the $\mathrm{CO}_{2}$ and the control floor. Thermal comfort was generally adequate on both floors. Annual energy savings of $12 \%$ were measured for the floor with DCV. Occupants of the DCV floor complained significantly more about the indoor environment than occupants of the control floor.

Fleury (1992) reported on the performance of a $\mathrm{CO}_{2}$ controlled ventilation system in a conference room. In this system, the fan motor speed was adjusted according to the $\mathrm{CO}_{2}$ concentration, but no information was provided on the specific control algorithm or setpoints. The measured $\mathrm{CO}_{2}$ concentrations in the space were between $630 \mathrm{mg} / \mathrm{m}^{3}(350 \mathrm{ppm}(\mathrm{v}))$ to $1530 \mathrm{mg} / \mathrm{m}^{3}(850 \mathrm{ppm}(\mathrm{v}))$, with one peak of $1980 \mathrm{mg} / \mathrm{m}^{3}$ (1100 ppm(v)). Based on occupant questionnaires, the air quality was rated from good to excellent. Another study was undertaken in a conference room set up to test DCV sensors, including $\mathrm{CO}_{2}$, volatile organic compounds and humidity (Ruud et al. 1991). The $\mathrm{CO}_{2}$ setpoints were not reported, but the indoor concentration never exceeded $1620 \mathrm{mg} / \mathrm{m}^{3}(900 \mathrm{ppm}(\mathrm{v}))$. Another demonstration in a conference room is reported by Huze et al. (1994). The ventilation rate was varied proportionally to the $\mathrm{CO}_{2}$ concentration within a $900 \mathrm{mg} / \mathrm{m}^{3}(500 \mathrm{ppm}(\mathrm{v}))$ band centered around $2160 \mathrm{mg} / \mathrm{m}^{3}$ (1200 ppm(v)). Limited results presented include a sample of the $\mathrm{CO}_{2}$ level and control signal for one day.

One of the most frequently cited demonstration projects took place in a small bank in Pasco, Washington (Gabel et al. 1986). This study involved the measurement of energy consumption, contaminant levels including nitrogen dioxide, formaldehyde, carbon monoxide and particulates, and occupant response based on a questionnaire. The study design included monitoring over the winter, spring and summer seasons, with one week of normal operation followed by one week of $\mathrm{CO}_{2}$ control. The system's economizer cycle operated normally throughout the test periods. They found that with the $\mathrm{CO}_{2}$ control system setpoint at $1800 \mathrm{mg} / \mathrm{m}^{3}(100 \mathrm{ppm}(\mathrm{v}))$ to $2160 \mathrm{mg} / \mathrm{m}^{3}$ $(1200 \mathrm{ppm}(\mathrm{v}))$, air leakage through the closed damper provided sufficient fresh air for typical occupancy, which was only $10 \%$ to $15 \%$ of design. That is, the indoor $\mathrm{CO}_{2}$ level never rose to the control setpoints. All measured contaminants were maintained below indoor standards. Based on a curve fit of the measured energy consumption to outdoor temperature for the two modes of outdoor air control, average energy savings of $7.8 \%$ for heating and cooling in six climates typical of Oregon and Washington were calculated. Based on the questionnaires, the occupants could not detect differences between background $\mathrm{CO}_{2}$ levels of $540 \mathrm{mg} / \mathrm{m}^{3}(300 \mathrm{ppm}(\mathrm{v}))$ and $1800 \mathrm{mg} / \mathrm{m}^{3}$ (100 ppm(v)). The occupants reported feeling warmer during DCV control, although the measured indoor temperatures were no different.

Another frequently-cited study took place in a Minnesota high school (Janssen et al. 1982). The ventilation system used $\mathrm{CO}_{2}$ and temperature to control outdoor air, and had separate dampers 
for temperature and $\mathrm{CO}_{2}$ control. Indoor contaminants, energy and subjective response of occupants were monitored. The measured energy savings were about $20 \%$. The occupant questionnaire showed that the subjects felt warmer with increased $\mathrm{CO}_{2}$ concentrations. Another study by the same group of researchers took place in a portion of a high school, which was retrofitted with a $\mathrm{CO}_{2}$-controlled system (Woods et al. 1982). During the early months of 1980, the system operated under alternate periods with conventional temperature control and with $\mathrm{CO}_{2}$ control. System performance was monitored, and the subjective responses of occupants were obtained. The system contained a set of outdoor air dampers that were controlled based on the $\mathrm{CO}_{2}$ concentration. These dampers modulated between fully closed and fully open damper positions, with the low setpoint at $5400 \mathrm{mg} / \mathrm{m}^{3}$ (3000 ppm(v)) and the high setpoint at $9000 \mathrm{mg} / \mathrm{m}^{3}$ (5000 ppm(v)). The results indicated the potential for significant energy savings. Occupants felt warmer when $\mathrm{CO}_{2}$ control operated despite the fact that there was no measurable temperature difference with and without $\mathrm{CO}_{2}$ control.

A study of two Finnish public buildings, one of which had $\mathrm{CO}_{2}$ controlled ventilation, included measurements of radon, particles and $\mathrm{CO}_{2}$ (Kulmala et al. 1984). No description of the $\mathrm{CO}_{2}$ control algorithm was reported. Daily energy savings were estimated at $13 \%$ to $20 \%$.

In several of the studies cited so far, the indoor $\mathrm{CO}_{2}$ concentration was often not high enough for the $\mathrm{CO}_{2}$ control system to operate. This may be due in part to the relatively low occupant density in office buildings. The application of $\mathrm{CO}_{2}$-based DCV is usually viewed as better suited to spaces where occupancy is more variable and where the peaks are associated with fairly high occupancy. Auditoria are good examples of such spaces, and there have been several case studies in these types of spaces. One such study took place in an auditorium with $\mathrm{CO}_{2}$ and timer control of ventilation at the Swiss Federal Institute of Technology in Zurich (Fehlmann et al. 1993). The measurements included system run time, energy use, climatic parameters and $\mathrm{CO}_{2}$ concentrations under winter and summer conditions. In addition, an occupant questionnaire was administered. The ventilation system had two stages of airflow capacity, with the first stage coming on at $1080 \mathrm{mg} / \mathrm{m}^{3}(600 \mathrm{ppm}(\mathrm{v}))$ and the second stage at $2340 \mathrm{mg} / \mathrm{m}^{3}(1300 \mathrm{ppm}(\mathrm{v}))$. The second stage would turn off at $1980 \mathrm{mg} / \mathrm{m}^{3}(1100 \mathrm{ppm}(\mathrm{v}))$, and the first stage at $1080 \mathrm{mg} / \mathrm{m}^{3}(600 \mathrm{ppm}(\mathrm{v}))$. With ventilation controlled by $\mathrm{CO}_{2}$, run time was $67 \%$ of the run time with timer control in summer and $75 \%$ in winter. Energy consumption with $\mathrm{CO}_{2}$ control was $80 \%$ less in summer and $30 \%$ less in winter. Questionnaire results indicated a higher perception of odors with $\mathrm{CO}_{2}$ control, especially in the summer. It was noted that the occupancy was very low compared to design, only about $10 \%$ to $20 \%$.

Zamboni et al. (1991) reported on field measurements in auditoria in Norway and Switzerland. In the Norwegian building, the $\mathrm{CO}_{2}$ setpoint was $1800 \mathrm{mg} / \mathrm{m}^{3}(1000 \mathrm{ppm}(\mathrm{v}))$, and the reported results include indoor temperature, $\mathrm{CO}_{2}$ concentration and age of air. In the Swiss building, there was a two-stage controller with the first setpoint at $1350 \mathrm{mg} / \mathrm{m}^{3}(750 \mathrm{ppm}(\mathrm{v}))$ and the second at $2340 \mathrm{mg} / \mathrm{m}^{3}$ (1300 ppm(v)). The researchers monitored energy consumption and indoor climate, and administered occupant questionnaires. Heating energy was reduced by $15 \%$ during one week of testing in the winter and by $75 \%$ in the summer. With $\mathrm{CO}_{2}$ control, there was less draft but more odor in summer.

Several demonstration projects have been conducted in so-called public spaces, including retail stores and recreational facilities, where occupancy is expected to be more variable and less predictable. Potter and Booth (1994) report on the performance of $\mathrm{CO}_{2}$-based DCV systems in eight public buildings. The authors note that the results point to some potential problems with $\mathrm{CO}_{2}$ control, but many of the results are presented simply in the form of plots of indoor $\mathrm{CO}_{2}$ concentration versus time. In an office building and a swimming pool facility, the indoor 
concentration never reached the $\mathrm{CO}_{2}$ setpoint. Building setpoints were variable and included $2250 \mathrm{mg} / \mathrm{m}^{3}$ (1250 ppm(v)), $3960 \mathrm{mg} / \mathrm{m}^{3}$ (2200 ppm(v)) and $4500 \mathrm{mg} / \mathrm{m}^{3}$ (2500 ppm(v)). Based on the results, the authors identify candidate building types for $\mathrm{CO}_{2}$ control as cinemas, theatres, bingo and snooker establishments, educational lecture theatres, teaching labs, meeting rooms, and retail premises. They considered the issues of maintenance and reliability, noting that no controllers in the buildings were marked for calibration due date or the date of last service.

Another study of two public spaces took place in a social club and a cinema in England (Anon 1986). The control algorithm was not described, but the $\mathrm{CO}_{2}$ setpoints were usually between $1260 \mathrm{mg} / \mathrm{m}^{3}(700 \mathrm{ppm}(\mathrm{v}))$ and $1800 \mathrm{mg} / \mathrm{m}^{3}(1000 \mathrm{ppm}(\mathrm{v}))$. The measured fuel savings were $17 \%$ in the club and $11 \%$ at the cinema. Warren (1982) reports on tests of energy savings with $\mathrm{CO}_{2}$ control in a theater and a retail store. Energy and cost savings estimates are based on short term tests in the building, and the dependence of the savings on ventilation system design parameters is discussed. The systems in the two buildings are not described in detail.

Chan et al. (1999) address the case of a lecture theater in Hong Kong where radon is known to be of concern. They propose a DCV system controlled by both $\mathrm{CO}_{2}$ and radon measurements to achieve acceptable IAQ while saving energy. Few details are presented.

Finally, Strindehag et al. (1990) and Strindehag and Norell (1991) reported on a number of examples of how outdoor air intake can be controlled by $\mathrm{CO}_{2}$ in a conference room, an auditorium, three offices and a school. The report contains descriptions of the buildings and the $\mathrm{CO}_{2}$ sensors, and notes that the $\mathrm{CO}_{2}$ setpoint was $1080 \mathrm{mg} / \mathrm{m}^{3}$ (600 ppm(v)). However, the control algorithms are not described, and no specific performance indicators are discussed. Satisfactory reliability of the system in the auditorium was reported after three years of operation.

The studies cited here show that $\mathrm{CO}_{2}$ control has been demonstrated in a wide variety of building types including offices, schools, and public. It is apparent in examining these studies that the $\mathrm{CO}_{2}$ control algorithm is often not described in sufficient detail to understand the system; in fact, some of the studies did not even report $\mathrm{CO}_{2}$ setpoints. In several of the demonstration projects, the building occupancy was insufficient to raise the indoor $\mathrm{CO}_{2}$ concentration enough to activate the $\mathrm{CO}_{2}$ control system. Several of the studies used occupant questionnaires to evaluate performance, with inconsistent results. In some cases, the occupants perceived the indoor environment with $\mathrm{CO}_{2}$ control positively. In other cases, there were more complaints, specifically with regards to odor during $\mathrm{CO}_{2}$ control. Several studies noted a feeling of increased warmth with elevated $\mathrm{CO}_{2}$ concentration despite the fact that the measured indoor temperatures were no higher. When considering these reports of occupant response, it must be kept in mind that the studies employed different questionnaires.

\subsection{Case Studies-Simulations}

As discussed above for field tests, the reported simulation case studies vary widely in both the description of important parameters and discussion of results. Most studies have focused on the potential energy savings of the $\mathrm{CO}_{2}$-based DCV systems, with $\mathrm{CO}_{2}$ concentrations reported as a measure of IAQ performance. A few studies have calculated concentrations of other pollutants. As with the field tests, the majority of the studies have involved office buildings, with others examining schools, retail buildings, restaurants and auditoria. Another important issue in simulations is the treatment of infiltration and interzone airflows, with most studies using assumed rates and a few studies employing a multizone airflow model. 
Recently, Brandemuehl and Braun (1999) investigated the energy impact of various combinations of six economizer and DCV strategies (no economizer, dry bulb economizer, and enthalpy economizer - each with and without DCV) for four types of buildings (office, large retail store, school, and sit-down restaurant) in twenty U.S. climates (including Los Angeles and Sacramento). Additional modeling assumptions included a $\mathrm{CO}_{2}$ setpoint of $1260 \mathrm{mg} / \mathrm{m}^{3}$ (700 ppm(v)) above ambient, thermostat setup or setback at night, HVAC fan shutdown during unoccupied hours, single-zone buildings with no infiltration, ventilation effectiveness of 0.85 , and minimum ventilation flows for non-DCV cases of $9.4 \mathrm{~L} / \mathrm{s}(20 \mathrm{cfm})$ per person, $4.7 \mathrm{~L} / \mathrm{s}$ (10 cfm) per person, 7.1 L/s $(15 \mathrm{cfm})$ per person, and $9.4 \mathrm{~L} / \mathrm{s}(20 \mathrm{cfm})$ per person for the office, retail, school, and restaurant cases, respectively. The DCV system resulted in significant reductions in heating energy use for all buildings and climates. Heating energy use reductions ranged from $40 \%$ for the office to $100 \%$ for the retail building (i.e., the solar and internal loads supplied all necessary heat) in Sacramento and from $75 \%$ for the office to $100 \%$ for the retail building in Los Angeles. The DCV system with enthalpy economizer required the least cooling energy use for all building types and climates. However, in some cases, much of the cooling energy reduction was due to the economizer, and use of DCV without an economizer can actually increase cooling energy use for dry climates. Cooling energy reductions ranged from about $10 \%$ to $20 \%$ for all buildings in Sacramento and Los Angeles. The authors also note that the savings associated with DCV are very dependent on the occupancy schedule and its relationship to the design occupancy used to set the fixed minimum ventilation rate of the base case. Also, for some types of buildings, additional ventilation may be required to maintain other contaminants at acceptable levels.

In an early report of a simulation study for an office, Knoespel et al. (1991) investigated the application of a $\mathrm{CO}_{2}$-based DCV system to a two-zone office space with both constant air volume (CAV) and variable air volume (VAV) HVAC systems. A multiple zone pollutant transport model was used and a ventilation airflow controller model was developed as modules for a transient thermal system simulation program (Klein 1994). Other existing modules of the program were used to calculate building energy consumption. Infiltration to the main zone was assumed constant at $0.2 \mathrm{~h}^{-1}$ and an interzone flow of $12 \mathrm{~L} / \mathrm{s}(24 \mathrm{cfm})$ from the main office to the conference room was included when the HVAC system was on. Knoespel compared the performance of six ventilation strategies including constant outdoor airflow at the ASHRAE Standard 62-1989 prescribed flow of $10 \mathrm{~L} / \mathrm{s}(20 \mathrm{cfm})$ per person, constant outdoor airflow at a "typical" rate of $0.7 \mathrm{~h}^{-1}$, minimum outdoor airflow at the typical rate with a temperature-based economizer, DCV with a step-flow control algorithm, DCV with step-flow control and a temperature-based economizer, and DCV with on-off control. In the step-flow control algorithm, the fraction of outdoor air in the circulation flow was changed in $20 \%$ steps depending on whether the measured $\mathrm{CO}_{2}$ concentration in either zone was above or below the specified limit. On-off control employed an algorithm in which outdoor airflow is set at $100 \%$ if the high $\mathrm{CO}_{2}$ setpoint is exceeded and at $0 \%$ if the $\mathrm{CO}_{2}$ concentration drops below the low setpoint. The setpoints used were $1440 \mathrm{mg} / \mathrm{m}^{3}$ (800 ppm(v)) and $1800 \mathrm{mg} / \mathrm{m}^{3}(1000 \mathrm{ppm}(\mathrm{v}))$. Simulations were performed for Miami, FL and Madison, WI. In Madison, the DCV strategies provided acceptable control of $\mathrm{CO}_{2}$ levels with coil energy savings from $9 \%$ to $28 \%$ for CAV systems and from $43 \%$ to $46 \%$ for VAV systems compared to the Standard 62-1989 prescribed rate strategy. The savings for Miami were of similar absolute magnitude but smaller percentages. These results did not include fan energy use. Compared to the economizer and constant outdoor airflow strategies at typical rates, the DCV strategies resulted in similar energy use with better control of $\mathrm{CO}_{2}$ concentrations for both CAV and VAV systems. 
Emmerich et al. (1994) applied the model developed by Knoespel et al. (1991) to examine the performance of DCV systems under less favorable conditions and to study the impact on nonoccupant generated pollutants. Emmerich used the same building, Madison location, and the HVAC systems described above but varied the simulated conditions to include a pollutant removal effectiveness as low as 0.5 and an occupant density up to $50 \%$ greater than design. For all cases examined, the DCV system reduced the annual cooling and heating loads from $4 \%$ to $41 \%$ while maintaining acceptable $\mathrm{CO}_{2}$ concentrations. In addition to requiring more energy use, the constant outdoor airflow strategy resulted in $\mathrm{CO}_{2}$ levels above $1080 \mathrm{mg} / \mathrm{m}^{3}$ (600 ppm(v)) for more than half of occupied hours for cases with poor pollutant removal effectiveness. Emmerich also examined the impact of DCV on non-occupant generated pollutants by modeling a constant source of a non-reactive pollutant located in the main office zone. Four ventilation strategies were compared including constant outdoor air at a prescribed rate based on ASHRAE Standard 62-1989, DCV with step control and setpoints of $1440 \mathrm{mg} / \mathrm{m}^{3}(800 \mathrm{ppm}(\mathrm{v}))$ and $1800 \mathrm{mg} / \mathrm{m}^{3}$ (1000 ppm(v)), DCV with a constant minimum outdoor airflow rate of $2.5 \mathrm{~L} / \mathrm{s}$ $(5 \mathrm{cfm})$ per person calculated using the multiple space method of ASHRAE Standard 62-1989, and DCV with scheduled purges of $100 \%$ outdoor air from 7:30 a.m. to 8:30 a.m. and 12:30 p.m. to 1:00 p.m. The non-occupant generated pollutant source strength was specified such that the system with constant outdoor airflow rate just met a short-term limit of $2 \mathrm{ppm}(\mathrm{v})$ and an 8-h average limit of $1 \mathrm{ppm}(\mathrm{v})$. (These concentrations cannot be converted to SI units, since this generic contaminant is not associated with any specific molecular weight.) Emmerich found that both the straight DCV and the DCV with minimum outdoor airflow rate failed to meet the pollutant concentration limits for both the CAV and VAV systems, but the DCV with scheduled purge strategy successfully limited the pollutant concentrations. The purge strategy increased building heating and cooling loads over the straight DCV strategy but still reduced the loads by $17 \%$ (CAV) and $25 \%$ (VAV) compared to the constant outdoor airflow case. The success of the purge strategy was attributed partially to the ability to schedule the purges when most needed.

In another study considering the effects of poor ventilation air mixing, Haghighat et al. (1993) simulated the performance of a $\mathrm{CO}_{2}$-based DCV system in a large office building in Montreal. The baseline ventilation system had a flow rate of $10 \mathrm{~L} / \mathrm{s}(20 \mathrm{cfm})$ per person, and a mixing parameter of 0.7 was used in the model. The DCV system used a minimum ventilation rate of $2.5 \mathrm{~L} / \mathrm{s}(5 \mathrm{cfm})$ per person, and the ventilation rate was adjusted each hour to maintain a $\mathrm{CO}_{2}$ concentration of $1440 \mathrm{mg} / \mathrm{m}^{3}(800 \mathrm{ppm}(\mathrm{v}))$. Infiltration was $0.4 \mathrm{~h}^{-1}$ with the HVAC system off and $0.04 \mathrm{~h}^{-1}$ with it on. Four cases of occupant density were examined. The DCV system saved from $7 \%$ to $15 \%$ in energy use, $2 \%$ to $6 \%$ in energy cost, and $7 \%$ to $17 \%$ in peak demand compared to a fixed ventilation rate strategy. In a follow-up study using the same office model with different infiltration, operating hours and other assumptions, Zmeureanu and Haghighat (1995) found energy consumption for the DCV system ranging from a $5 \%$ decrease to a $2 \%$ increase. However, because of peak demand reductions, annual energy cost savings ranging from $3 \%$ to $26 \%$ were found.

Sorensen (1996) also describes simulations performed for a two-zone office with a conference room. A unique aspect of this study is its focus on examining the short term dynamics of the system by simulating a ten hour period with one second time steps and detailed modeling of the HVAC system. A VAV system with dual temperature and $\mathrm{CO}_{2}$ control and CAV system without $\mathrm{CO}_{2}$ control are simulated. Because a detailed VAV system model is used, the control algorithm is more complex than in most studies reviewed and involves both dampers and fans. When the $\mathrm{CO}_{2}$ concentration is above an upper limit of $1620 \mathrm{mg} / \mathrm{m}^{3}(900 \mathrm{ppm}(\mathrm{v}))$, the damper actuator position increases by $1 \%$. If the concentration remains above the upper limit, the position continues to increase until it is fully open or until it drops below the limit. After the damper is 
fully open, a concentration above the upper limit will increase the fan speed by $5 \%$ until the fan reaches maximum speed or the concentration falls below the limit. The algorithm also uses a lower limit of $1260 \mathrm{mg} / \mathrm{m}^{3}$ (700 ppm(v)) to decrease fan speed and damper position. Detailed results are not presented, but transient $\mathrm{CO}_{2}$ concentrations and temperatures are presented and it is stated that the VAV system used $31 \%$ less energy than the CAV system for a cold ambient condition.

Another recent study of office applications (Carpenter 1996 and Enermodal 1995) examined both the energy and IAQ impacts of $\mathrm{CO}_{2}$-based DCV in a mid-sized commercial building complying with ASHRAE Standard 90.1 in four climate zones (Chicago, Nashville, Phoenix, and Miami). Simulations were performed using a combination of an energy analysis program (Enermodal 1990) and the multizone pollutant transport program CONTAM87 (Axley 1988). Three HVAC systems (single-zone, multizone, and VAV) and 5 ventilation control strategies (fixed ventilation rate, DCV with building return air controlled to $1800 \mathrm{mg} / \mathrm{m}^{3}(1000 \mathrm{ppm}(\mathrm{v}))$ and $1440 \mathrm{mg} / \mathrm{m}^{3}$ (800 ppm(v)), DCV with floor return controlled to $1000 \mathrm{ppm}(\mathrm{v})$, and DCV with each zone controlled to $1800 \mathrm{mg} / \mathrm{m}^{3}$ (1000 ppm(v)) were analyzed. The DCV control algorithm was not described in detail. For single-zone systems, the DCV strategy reduced heating energy by about $30 \%$ for a setpoint of $1800 \mathrm{mg} / \mathrm{m}^{3}(1000 \mathrm{ppm}(\mathrm{v}))$ and by $20 \%$ for a setpoint of $1440 \mathrm{mg} / \mathrm{m}^{3}$ (800 ppm(v)). The DCV system with a setpoint of $800 \mathrm{ppm}(\mathrm{v})$ also reduced average $\mathrm{CO}_{2}$ concentrations by $90 \mathrm{mg} / \mathrm{m}^{3}$ (50 ppm(v)) to $160 \mathrm{mg} / \mathrm{m}^{3}$ (90 ppm(v)) compared to the fixed ventilation rate strategy. The DCV strategies had little effect on cooling energy, because the DCV system tended to reduce ventilation during the cooler morning and evening hours and increase ventilation during the warmer middle of the day. For VAV systems, the energy savings were similar to those with single-zone systems. For multizone systems, the reduction in heating energy was similar in absolute terms but was smaller in percent (5\% to $12 \%)$ because of a larger total heating load. DCV with a setpoint of $1800 \mathrm{mg} / \mathrm{m}^{3}(1000 \mathrm{ppm}(\mathrm{v}))$ resulted in average $\mathrm{CO}_{2}$ concentrations $130 \mathrm{mg} / \mathrm{m}^{3}$ (70 ppm(v)) to $270 \mathrm{mg} / \mathrm{m}^{3}$ (150 ppm(v)) higher than the fixed ventilation strategy, while a setpoint of $1440 \mathrm{mg} / \mathrm{m}^{3}(800 \mathrm{ppm}(\mathrm{v}))$ kept concentrations lower than the fixed strategy and the maximum below $1800 \mathrm{mg} / \mathrm{m}^{3}(1000 \mathrm{ppm}(\mathrm{v}))$ in all zones. Providing additional sensors in return duct of each floor had little impact on energy use and IAQ. Installing sensors in each zone ensured that the concentration in each zone stayed below $1800 \mathrm{mg} / \mathrm{m}^{3}$ (1000 ppm(v)) but at a slightly higher energy use. The performance of DCV with sensors set at $1800 \mathrm{mg} / \mathrm{m}^{3}(1000 \mathrm{ppm}(\mathrm{v}))$ in each zone was similar to central control with a setpoint of $1440 \mathrm{mg} / \mathrm{m}^{3}$ (800 ppm(v)). Formaldehyde concentrations were also simulated to evaluate the impact of DCV strategies on pollution from a non-occupant source. None of the DCV strategies controlled the formaldehyde concentrations as well as the fixed ventilation strategy. It was suggested that a morning purge should be included in a DCV strategy when non-occupant generated pollutants are a concern, but this option was not simulated. Different DCV control algorithms including on-off, linear proportional, proportional-integral-derivative (PID), and the Vaculik method (discussed later in this paper) were discussed but not simulated.

Wang and Jin (1998) also simulate the performance of $\mathrm{CO}_{2}$-based DCV for an office with a focus on describing and evaluating a control algorithm that can adjust ventilation rates based on estimated occupancy. Three different occupancy estimation algorithms (steady state, approximate dynamic detection, and exact dynamic detection) were compared for a single wellmixed zone with three different occupant densities and patterns. Both dynamic detection methods detected occupancy with high accuracy and the change of occupancy with a fast response time. Later, Wang and Jin (1999) experimentally verified the capability of the algorithms. 
Wang and Jin then performed simulations to compare the IAQ and energy performance of four ventilation strategies (DCV using approximate dynamic detection algorithm, DCV with a $\mathrm{CO}_{2}$ upper limit of $1800 \mathrm{mg} / \mathrm{m}^{3}$ (1000 ppm(v)), DCV with $\mathrm{CO}_{2}$ upper limit of $1800 \mathrm{mg} / \mathrm{m}^{3}$ (1000 ppm(v)) upper limit and $1440 \mathrm{mg} / \mathrm{m}^{3}$ (800 ppm(v)) lower limit, and constant outdoor air) for an eight-zone open-plan office with two different occupant densities. The office had a combination of CAV and VAV ventilation systems. Simulations were performed for single days of summer and spring Hong Kong weather. The study found the two DCV systems based on direct $\mathrm{CO}_{2}$ measurement were able to control $\mathrm{CO}_{2}$ levels as well as the occupancy detection method but could not maintain constant ventilation rates per occupant. Unfortunately, the $\mathrm{CO}_{2}$ concentrations results indicate a potential major flaw in the model assumptions. At the end of the day, the ventilation system is turned off and there is no infiltration overnight resulting in initial $\mathrm{CO}_{2}$ concentrations of $1440 \mathrm{mg} / \mathrm{m}^{3}$ (800 ppm(v)) to $1800 \mathrm{mg} / \mathrm{m}^{3}(1000 \mathrm{ppm}(\mathrm{v}))$. This assumption masks likely significant differences in system performance during the morning hours as $\mathrm{CO}_{2}$ concentration increases from background levels. Also, the authors conclude that this would result in inadequate indoor air quality but provide no justification. Compared to the constant ventilation strategy, all three DCV strategies were found to reduce coil loads about $8 \%$ for spring weather and from $12 \%$ to $18 \%$ for summer weather.

Meckler (1994) also simulated the application of $\mathrm{CO}_{2}$-based DCV in an office building. The energy performance of an idealized DCV system with the ventilation rate varied to maintain $1440 \mathrm{mg} / \mathrm{m}^{3}$ (800 ppm(v)) and $1660 \mathrm{mg} / \mathrm{m}^{3}$ (920 ppm(v)) (i.e., no control algorithm modeled) was compared to a baseline system with a constant ventilation rate of $10 \mathrm{~L} / \mathrm{s}(20 \mathrm{cfm})$ per person. The office building has ten floors with two outdoor air handling units for each floor, a central hydronic heating and cooling plant, and an economizer. Both energy and economic impacts are presented for five U.S. cities (Miami, Atlanta, Washington, D.C., New York, and Chicago). Reported energy savings ranged from less than $1 \%$ to $3 \%$ for electricity and from $16 \%$ to $22 \%$ for gas. Payback periods of 1.5 years to 2.2 years were estimated for all cities.

In a recent study with a focus on humid climates, Shirey and Rengarajan (1996) simulated the impact of a $\mathrm{CO}_{2}$-based DCV system in a $400 \mathrm{~m}^{2}\left(4000 \mathrm{ft}^{2}\right)$ office located in Miami, Orlando, and Jacksonville to examine the impacts of ASHRAE Standard 62-1989 ventilation rates on indoor humidity levels. The baseline system, a conventional direct expansion (DX) air-conditioning system with a sensible heat ratio (SHR) of 0.78 , was unable to keep the indoor humidity below the target of $60 \%$ relative humidity $(\mathrm{RH})$ when the ventilation rate was increased from $2.5 \mathrm{~L} / \mathrm{s}$ to $10 \mathrm{~L} / \mathrm{s}(5 \mathrm{cfm}$ to $20 \mathrm{cfm}$ ) per person. System modifications considered included a low-SHR DX air-conditioner, a high efficiency low-SHR air-conditioner, a conventional air-conditioner with $\mathrm{CO}_{2}$-based DCV, a conventional air-conditioner with an enthalpy recovery wheel, a heat pipe assisted air-conditioner, and a conventional air-conditioner with a separate $100 \%$ outdoor air DX unit. The operation of the DCV system was simulated by matching ventilation rates to occupancy profiles. Four alternative systems (DCV, enthalpy wheel, heat pipe, and $100 \%$ outdoor air DX unit) maintained acceptable humidity levels for greater than $97 \%$ of occupied hours. Of the systems with acceptable humidity performance, only the DCV and enthalpy wheel options did so with less than $5 \%$ increases in annual HVAC energy use compared to the conventional system with a ventilation rate of $2.5 \mathrm{~L} / \mathrm{s}(5 \mathrm{cfm})$ per person. The DCV system also significantly lowered the peak heating demand in Orlando and Jacksonville. An economic analysis showed that the DCV system resulted in annual HVAC operating cost increases of $7 \%$ or less, first cost increases of about $14 \%$, and life cycle cost increases of about $12 \%$ compared to the system with $2.5 \mathrm{~L} / \mathrm{s}(5 \mathrm{cfm})$ per person. A case with high internal loads was also examined, with the DCV and enthalpy wheel systems again resulting in the best performance for the smallest increases in cost. 
In a recent follow-up study, Davanagere et al. (1997) applied the same methodology with many of the same assumptions as Shirey and Rengarajan (1996) to study HVAC system options including $\mathrm{CO}_{2}$-based DCV in a Florida school. As in the previous study, the baseline for comparisons was a conventional system with ventilation as required by ASHRAE Standard 621981. In addition to DCV, the options simulated included the conventional system with ASHRAE Standard 62-1989 ventilation rates and various combinations of pretreating outdoor air, thermal energy storage, enthalpy recovery wheels, gas-fired desiccant systems, and cold air distribution systems. Results reported included energy use, humidity levels, first costs and lifecycle costs. In general, the DCV system resulted in the smallest or close to the smallest increases in energy costs and installed first costs compared to the baseline system. The thermal energy storage system options generally resulted in the smallest increases (or even decreases) in peak cooling demands and life-cycle costs. DCV was the only option that reduced peak heating demands. Although the DCV system reduced humidity levels compared to the baseline system, many of the other simulated options controlled humidity better.

Nakahara (1996) also discusses a simulation of DCV in a school building with an emphasis on multiple zones and the potential benefit of zoning the ventilation system based on the level of $\mathrm{CO}_{2}$ demand instead of based on room position. However, little detail is provided on the model, and the baseline for the resulting potential thermal load reduction of $46 \%$ is not clearly defined.

In addition to offices and schools, public spaces have also been the subject of DCV simulation studies. Warren and Harper (1991) evaluated the potential heating energy savings for a $\mathrm{CO}_{2}-$ based DCV system applied to an auditorium in London. Energy simulations were performed using a building energy analysis program (Clarke and McLean 1986) with ventilation rates calculated separately based on occupancy profiles. Assumptions included $\mathrm{CO}_{2}$ generation of $4.7 \times 10^{-6} \mathrm{~m}^{3} / \mathrm{s}\left(1.7 \times 10^{-4} \mathrm{ft}^{3} / \mathrm{s}\right)$ per person, auditorium volume of $11,150 \mathrm{~m}^{3}\left(406,000 \mathrm{ft}^{3}\right)$, high $\mathrm{CO}_{2}$ setpoint of $1800 \mathrm{mg} / \mathrm{m}^{3}$ (1000 ppm(v)), peak daily occupancy of 629, and infiltration rate of $0.4 \mathrm{~h}^{-1}$. Three ventilation scenarios were compared including $100 \%$ outdoor airflow at a rate of $5,020 \mathrm{~L} / \mathrm{s}(10,000 \mathrm{cfm}), \mathrm{DCV}$ with a minimum outdoor airflow rate of 3,770 L/s $(7,500 \mathrm{cfm})$, and DCV with no minimum. The DCV with minimum outdoor airflow rate rarely exceeded the minimum rate to maintain $\mathrm{CO}_{2}$ concentrations below $1800 \mathrm{mg} / \mathrm{m}^{3}(1000 \mathrm{ppm}(\mathrm{v}))$ and saved $26.4 \%$ in heating energy use compared to the $100 \%$ outdoor airflow case. The DCV with no minimum saved $53.3 \%$.

Ogasawara et al. (1979) evaluated the potential energy savings for a DCV system in a $30,000 \mathrm{~m}^{2}$ $\left(320,000 \mathrm{ft}^{2}\right)$ department store in Tokyo, Japan. Three ventilation strategies were compared including fixed outdoor air at design rate, manual control with maximum ventilation on Sundays (the busiest day) and half of that on weekdays, and DCV. The DCV algorithm used was proportional control with a closed damper at $1440 \mathrm{mg} / \mathrm{m}^{3}(800 \mathrm{ppm}(\mathrm{v}))$ and a fully open damper at $1800 \mathrm{mg} / \mathrm{m}^{3}(1000 \mathrm{ppm}(\mathrm{v}))$. Infiltration assumptions were not specified. Energy use was calculated for 4 cooling months and 4 heating months. The DCV system reduced energy use by $40 \%$ for the cooling season and by $30 \%$ for the heating season. An economic analysis showed an advantage for the DCV system.

Feher and Ambs (1997) reported a study in which measurements of $\mathrm{CO}_{2}$ concentrations in a school building were used to estimate occupancy and to simulate operation of a DCV system. Four independent zones of the school building, which had recently had the outdoor airflow rate increased above design by $50 \%$, were included in the energy simulations. PID control was simulated although it was concluded that there was little additional benefit compared to proportional control. No infiltration, interzonal airflow, or air change effectiveness parameters were included in the model. A minimum outdoor airflow of $1 \mathrm{~h}^{-1}$ was provided. Annual HVAC 
energy savings compared to the original design rates were estimated to range from $3 \%$ for the classroom zone up to $17 \%$ for the auditorium zone depending on the control approach.

In a very unique application, Dounis et al. (1996) investigated the potential application of $\mathrm{CO}_{2-}$ based DCV to control ventilation rates for a building with natural ventilation. Simulations were performed in which window opening was adjusted based on measured $\mathrm{CO}_{2}$ concentrations. Due to concerns over the constant variation of natural ventilation driving forces, fuzzy logic was used instead of conventional on-off or PID control. Carbon dioxide concentrations, window openings, and air temperatures are presented for a simulated day. Although performance was not as good as expected, the authors conclude that the feasibility of such a system was demonstrated.

The simulation case studies reviewed indicated energy savings for DCV systems between $4 \%$ and over $50 \%$ compared to ASHRAE Standard 62-1989 or other design ventilation rates. The energy savings varied widely depending on type of building, control algorithm, building location, assumed occupancy and other assumptions. No parametric or sensitivity analysis has been performed to determine which variables have the most influence on potential energy savings. Also, energy savings are reported with respect to different baseline cases in the different studies. A small number of the studies examined peak demand, economic impacts, humidity and concentrations of other pollutants. These studies verified the concern for increased concentrations of non-occupant generated pollutants, and one study examined potential solutions including scheduled purges. Shortcomings of most of the studies included inadequate treatment of infiltration and interzone airflows and control algorithms.

\subsection{Sensor Performance and Location}

The performance of a $\mathrm{CO}_{2}$-based DCV system will clearly depend on the measured $\mathrm{CO}_{2}$ concentration as reported by the system sensors. Key issues related to these sensors are their accuracy, reliability, and location in the building. This section discusses the research that has been done on sensor performance and location.

\section{Sensor Performance}

In the most extensive report on sensor performance, Fahlen et al. (1991 and 1992) describe an evaluation of the performance characteristics of two $\mathrm{CO}_{2}$, nine humidity, and five mixed-gas sensors in both lab tests and long term field tests. The lab tests consisted of both performance and environmental tests, while the field tests consisted of a repeat of the performance tests after the sensors had been installed in the field for 11 months. The $\mathrm{CO}_{2}$ sensors displayed acceptable performance for control purposes with a deviation of less than $50 \mathrm{mg} / \mathrm{m}^{3}(30 \mathrm{ppm}(\mathrm{v}))$ at a level of $1800 \mathrm{mg} / \mathrm{m}^{3}(1000 \mathrm{ppm}(\mathrm{v}))$. However, the following problems were identified: timeconsuming calibration, sensitivity to humidity, and cross-sensitivity to voltage, temperature and tobacco smoke. Characteristic curves comparing the sensor performance before and after the field trial are presented. At $1800 \mathrm{mg} / \mathrm{m}^{3}(1000 \mathrm{ppm}(\mathrm{v}))$, the deviation from the original result was between $0 \mathrm{mg} / \mathrm{m}^{3}(\mathrm{ppm}(\mathrm{v}))$ and $180 \mathrm{mg} / \mathrm{m}^{3}(100 \mathrm{ppm}(\mathrm{v}))$.

Meier (1993) reports on the performance of two $\mathrm{CO}_{2}$ and 17 mixed-gas sensors in five different facilities at the University of Zurich. Measurements of $\mathrm{CO}_{2}$, air quality units (AQU), and occupancy are presented for one day in a restaurant. It is concluded that both mixed-gas and $\mathrm{CO}_{2}$ sensors are suitable for registering the occupancy level in the restaurant and can provide the reference variable for $\mathrm{DCV}$. The results of the mixed-gas sensors and $\mathrm{CO}_{2}$ sensors are compared, but no conclusion is reached as to which sensor type is more suitable.

Recently, Okamoto et al. (1996) described the development and field testing of a $\mathrm{CO}_{2}$ sensor employing solid-state electrolyte technology. The sensor is stated as having an accuracy of 
$\pm 20 \%$ and acceptable sensitivity to temperature, humidity, and miscellaneous gases. However, the basis of the statements (i.e., laboratory test results) is not presented. Limited field tests of the sensors in a school and two conference rooms are described. In these tests, the sensors were used as monitors with low, medium and high setpoints of $1260 \mathrm{mg} / \mathrm{m}^{3}(700 \mathrm{ppm}(\mathrm{v})), 2520 \mathrm{mg} / \mathrm{m}^{3}$ (1400 ppm(v)), and $4500 \mathrm{mg} / \mathrm{m}^{3}$ (2500 ppm(v)) but were not used to control the ventilation system directly.

Several other reports contain more limited discussion of $\mathrm{CO}_{2}$ sensor performance. The literature review by Raatschen (1990) describes the various types of sensors available. The $\mathrm{CO}_{2}$ sensors discussed use infrared absorption and are available as two types - photoacoustic and photometric. No actual performance tests were conducted, but a summary of manufacturers' data is provided. Houghton (1995) also describes available sensor types; manufacturer's specifications are presented for five sensors available in the U.S. Issues of accuracy, drift, and temperature and pressure sensitivity are also addressed, although no independent performance tests are reported. Helenelund (1993) also discusses the various sensor options available for DCV systems but does not report on their performance. Based on other published reports, interviews and obtained test results, the suitability of various sensors for different types of facilities is presented from the point of view of both technological and economical performance. In a field test, Sodergren (1982) reported that the sensor calibration drifted from $180 \mathrm{mg} / \mathrm{m}^{3}(100 \mathrm{ppm}(\mathrm{v}))$ to $270 \mathrm{mg} / \mathrm{m}^{3}$ (150 ppm(v)) during the study. In another field test, Ruud et al. (1991) found that one $\mathrm{CO}_{2}$ sensor had to be connected to the supply voltage for several days before the output signal became stable.

\section{Sensor Location}

In an experimental study aimed at determining the proper location for DCV sensors within a room, Stymne et al. (1990) investigated the dispersion of $\mathrm{CO}_{2}$ from simulated people in a fourroom test house. The following design factors were discussed: transfer of $\mathrm{CO}_{2}$ from the sources to different locations (referred to as transfer probability), the expected equilibrium concentration at a location, the rate constant of approaching equilibrium from a nonequilibrium state, and concentration fluctuations. The total ventilation flow rate to the test house was varied between two levels with the fraction to each room remaining constant. People were simulated by metallic bodies heated by a $100 \mathrm{~W}$ lamp and emitting $0.0069 \mathrm{~L} / \mathrm{s}(0.015 \mathrm{cfm})$ of $\mathrm{CO}_{2}$ mixed with prewarmed air. Measurements were taken at 19 locations. Tracer gas measurements were also performed. The measurements showed that good mixing was achieved in rooms with closed doors, and therefore the sensor location is not critical. However, if a room is connected to other spaces by open doors, large differences and instabilities in the $\mathrm{CO}_{2}$ concentration may occur. The distribution pattern of the tracer gas was similarly nonuniform, indicating that the cause of the distribution pattern is air movement through open doorways and its interaction with air movement from the heated bodies, radiators, cold external walls, and the jet from the inlet duct. It is recommended to place the DCV sensor at mid-height in a room and away from doorways, radiators, windows, people and air inlet devices if possible. It is also recommended that the DCV system have a large time constant in order not to react to the fluctuations in concentration due to nonuniform distribution patterns.

In a follow-up study, Stymne et al. (1991) investigated the $\mathrm{CO}_{2}$ distribution pattern in an office room with a displacement ventilation system. People were simulated by heated dummies emitting tracer gas. Graphs of iso-concentration contours are presented for several cases. The lack of normal disturbances such as body movements, breathing, heat sources, lighting, and solar heat gain is mentioned as a limitation of the study. It is shown that pollutants emitted from the 'people' are transported to the upper mixed zone in the room and that pollutants emitted at a 
small heat source or near the wall accumulate below the interface between the upper and lower zones. The interface is displaced about $0.2 \mathrm{~m}(0.66 \mathrm{ft})$ upwards around the heated bodies, ensuring the occupants better air quality than the surrounding air, even if they are above the interface. A test with a mixing ventilation system showed a similar plume above the heated dummies but no stratification outside the plume. It is concluded that DCV in a displacement ventilated room is a suitable means of controlling the level of the interface between the uncontaminated air in the upper zone and the polluted air in the lower zone. The sensors should be located at the height of the occupants' heads. Also, the setpoint should be lower than usual, for example below $1440 \mathrm{mg} / \mathrm{m}^{3}$ (800 ppm(v)), so that the DCV system will be activated.

A common alternative to locating DCV sensors in individual rooms is to locate them in the ventilation system return ductwork. Reardon and Shaw (1993) and Reardon et al. (1994) compared $\mathrm{CO}_{2}$ concentrations in the central return air shafts, individual floor return intakes, and occupied space in a 22-story office building. Measurements showed that the individual floor return grilles represented the spatial average concentrations in the occupied space, and that the measurements at the top of the central return shafts represented the concentrations at the floor return intakes. Therefore, it was concluded that the top of the return shafts is an appropriate location for the sensors of a DCV system. However, the setpoint should be adjusted (lowered) to account for variability in the occupied zones to avoid high local exposures.

Bearg (1994) also compares the merits of single and multiple point DCV systems. A system is described with multiple sampling points and a single detector installed in a 5-story building. In addition to operating the DCV system, advantages credited to the multipoint system include identifying both leakages in the system and episodes of increased outdoor contamination such as vehicle exhaust at a loading dock. Also, the use of a single detector ensures that differences in measured concentrations for different sampling points are not due to calibration differences. Such a system could also be automatically recalibrated with a known $\mathrm{CO}_{2}$ concentration. Houghton (1995) discusses this multipoint system including its accuracy and automatic calibration advantages. However, the system is claimed to be more costly than a system with multiple detectors and a central computer. Some data collected by the multipoint system is presented.

Several other reports briefly discuss sensor location issues. In another field test, Sodergren (1982) presented graphs of the $\mathrm{CO}_{2}$ concentration at multiple locations in an office but did not make specific recommendations on sensor location. In a test in a conference room, Ruud et al. (1991) found that concentrations measured at the wall and in the exhaust air were nearly identical with the wall-mounted sensor having a 2-min delay compared to the exhaust air. In a simulation study of a DCV system applied to an office building with floors having different occupant densities, Enermodal (1995) found that a system with sensors in the return duct of each floor had little impact on IAQ and energy use compared to a system with a sensor in the central return. Installing sensors in each zone ensured $\mathrm{CO}_{2}$ concentrations below $1800 \mathrm{mg} / \mathrm{m}^{3}$ (1000 ppm(v)) (the setpoint) in all zones and increased energy use slightly, but at a higher installation cost due to the additional sensors. Central control with a setpoint of $1440 \mathrm{mg} / \mathrm{m}^{3}$ $(800 \mathrm{ppm}(\mathrm{v}))$ offered similar performance to individual zone control with a setpoint of 1800 $\mathrm{mg} / \mathrm{m}^{3}(1000 \mathrm{ppm}(\mathrm{v}))$, but at a much lower installation cost.

Although many DCV studies have touched on the subjects of sensor performance and location, only a few have examined these issues in detail. In general, sensor performance characteristics have been found to be adequate for controlling a DCV system although concerns about calibration and sensitivity to humidity and temperature have been expressed. Sensor calibration concerns are being addressed by either use of a second detector tuned to a wavelength that isn't 
absorbed by $\mathrm{CO}_{2}$ to provide a reference value to correct for sensor drift over time or "selfcalibrating" by checking the $\mathrm{CO}_{2}$ level at night when indoor concentrations are expected to drop to outdoor levels (Schell and Int-Hout 2001). Contradicting opinions on sensor location have been expressed with some studies advocating a system with a single central measurement in the HVAC return system and others preferring a system with multiple measurement points.

\subsection{Application}

In addition to the studies of the performance of $\mathrm{CO}_{2}$-based DCV systems, there have also been a growing number of reports that describe how to apply these systems. These reports range from general descriptions of $\mathrm{CO}_{2}$-based DCV to detailed descriptions of control algorithms. This section reviews a number of these reports.

One of the earliest discussions of using $\mathrm{CO}_{2}$ to control outdoor air intake as a means of saving energy was presented by Kusuda (1976). This paper presented some of the theoretical background of how indoor $\mathrm{CO}_{2}$ concentrations vary as a ventilation system is turned on and off. Sample calculations showed potential energy savings of $40 \%$ for an office space. Another early discussion of the energy savings potential of $\mathrm{CO}_{2}$ control was presented by Turiel et al. (1979). This paper discussed a number of DCV control options including water vapor and concluded that $\mathrm{CO}_{2}$ control appeared to be the most satisfactory approach.

Recently, one of the more detailed discussions of the application of DCV was reported by Schell et al. 1998. DCV topics covered include potential energy savings with DCV, determining locations for $\mathrm{CO}_{2}$ sensors, control strategies (including setpoint, proportional, and exponential or PID), consideration of outdoor levels of $\mathrm{CO}_{2}$, estimation of building ventilation rates using $\mathrm{CO}_{2}$, models for selection of DCV strategy, and benefits of DCV. Additionally, Schell et al. discuss applying $\mathrm{CO}_{2}$-based DCV in compliance with ASHRAE Standard 62-1989 (ASHRAE 1990).

A general discussion of the principles of DCV in office buildings is presented by Davidge (1991) and Houghton (1995). These papers discuss the circumstances under which DCV might be expected to be most effective including the existence of unpredictable variations in occupancy, a building and climate where heating or cooling is required for most of the year, and low pollutant emissions from non-occupant sources. Davidge points out that when such a system is considered, one must address the base ventilation rate that is not controlled by DCV in order to control these non-occupant pollutant sources. The impact of free cooling on DCV systems is also discussed, noting that long periods of free cooling will reduce the potential energy savings. The potential for purge ventilation, both before and after occupancy, to control non-occupant sources is also discussed.

Similar discussions of the application of $\mathrm{CO}_{2}$-based DCV are presented by Houghton (1995) and in an application guide published by Telaire (n.d.). These publications contain background information on $\mathrm{CO}_{2}$ control of ventilation and describe the potential energy savings benefits. Strategies for the use of $\mathrm{CO}_{2}$-based DCV are also described including simple setpoint control where the outdoor air intake damper is either open or closed depending on the indoor $\mathrm{CO}_{2}$ concentration, proportional control in which the intake damper or outdoor air fan flow is proportional to the $\mathrm{CO}_{2}$ concentration, and PID (proportional-integral-derivative) control which considers the rate of change in the $\mathrm{CO}_{2}$ concentration. Recommendations are made on the application of these techniques based on the occupancy level.

Descriptions of specific control algorithms are presented by Vaculik and Plett (1993), Federspiel (1996), Bjorsell (1996), and the Telaire application guide (n.d.). In their paper, Vaculik and Plett discuss the principles of $\mathrm{CO}_{2}$-based DCV including setpoint and proportional control. They then 
describe a control approach that accounts for differences between $\mathrm{CO}_{2}$ concentration at the measurement location and the critical location in the building and in which the control setpoint is adjusted to account for differences between the measured concentration and the setpoint.

Federspiel (1996) also reports on a control algorithm, referred to as On-Demand Ventilation Control (ODVC), and presents a simple simulation to demonstrate its performance. The ODVC strategy attempts to set the ventilation rate proportional to the occupant density even under transient conditions by using a well-mixed single zone model to estimate the current $\mathrm{CO}_{2}$ generation rate from measured concentrations and airflows. A simple example is presented to show the ODVC strategy controls the $\mathrm{CO}_{2}$ concentration below $1800 \mathrm{mg} / \mathrm{m}^{3}$ (1000 ppm(v)) by reacting quickly to a step change in occupancy, while a strategy of PI control of measured $\mathrm{CO}_{2}$ concentration allows $\mathrm{CO}_{2}$ to overshoot the setpoint value. Issues regarding the impact on energy use and the potential effect of well-mixed single zone model inadequacies are not addressed. Ke and Mumma (1997) and Wang and Jin (1998) describe similar algorithms.

Bjorsell (1996) also focuses on the description and simulation of a DCV control algorithm, presenting a simple simulation example. The control algorithm, called Linear Quadratic, attempts to calculate the optimal system flow to minimize a cost function that depends on concentration and ventilation flow. However, the cost function is not specified and, although the control method may be optimal with respect to a given cost function, it also depends on all physical data being known and may not be practical to implement.

As mentioned earlier in the sections on field and simulation cases studies, a variety of control setpoints have been used, and many descriptions of the application of $\mathrm{CO}_{2}$ control contain only limited discussion of how to determine the appropriate setpoint. Schultz and Krafthefer (1993) present a method for determining a $\mathrm{CO}_{2}$ setpoint based on the Indoor Air Quality procedure in ASHRAE Standard 62. This method employs a two-zone model of the ventilated space and considers the ventilation efficiency of the space. Nomographs are presented for use in determining the $\mathrm{CO}_{2}$ setpoints.

The use of $\mathrm{CO}_{2}$ control of outdoor air is discussed relative to other approaches of outdoor air control in papers by Elovitz (1995) and by Janu et al. (1995). Elovitz discusses various options for controlling minimum outdoor air intake rates in VAV systems including: sequencing supply and return fans; controlling return or relief fans based on building pressure; measuring outdoor air intake rates directly; fan tracking; controlling the pressure in the intake plenum; outdoor air injection fans; and, $\mathrm{CO}_{2}$ control. Advantages and disadvantages of each approach are discussed. Elovitz points out that $\mathrm{CO}_{2}$ control does not necessarily assure satisfactory indoor air quality, depending on the existence and strength of contaminant sources that are not proportional to the number of occupants. Janu et al. (1995) discuss some of the same methods of outdoor airflow control and raise the same cautions regarding $\mathrm{CO}_{2}$ control and non-occupant contaminant sources.

In addition to a general discussion of DCV, Meier (1995) reports a sensitivity analysis on parameters affecting the payback period for modifying a conventional ventilation system to add DCV capability. Although few details of the calculation are presented, the total airflow rate is reported as the most significant parameter determining payback period. However, operating hours were also found to be significant. More recently, Meier (1998) provided estimated potential energy-cost savings for a range of DCV applications based on case studies and experiences of control companies. These estimates and additional ones from Mansson (1994) are presented in Table 2. Mansson provides background information on $\mathrm{CO}_{2} \mathrm{DCV}$ systems, discusses strategies for base and variable ventilation rates based on application type, and presents 
a six-step flowchart for determining the feasibility of DCV for an application. As expected, the energy savings in Table 2 are largest for high density spaces with generally variable occupancy, such as the various halls, theatres and cinemas. The lowest savings are seen in the office spaces, which generally have lower occupancy densities with less variation than the other spaces.

\begin{tabular}{|l|l|}
\hline Application & Energy-cost savings range \\
\hline Schools & $20 \%$ to $40 \%$ \\
\hline Day nurseries & $20 \%$ to $30 \%$ \\
\hline Restaurants, canteens & $20 \%$ to $50 \%$ \\
\hline Lecture halls & $20 \%$ to $50 \%$ \\
\hline Open-plan offices (40\% average occupancy) & $20 \%$ to $30 \%$ \\
\hline Open-plan offices (90\% average occupancy) & $3 \%$ to $5 \%$ \\
\hline Entrance halls, booking halls, airport check-in areas & $20 \%$ to $60 \%$ \\
\hline Exhibition halls, sports halls & $40 \%$ to $70 \%$ \\
\hline Assembly halls, theatres, cinemas & $20 \%$ to $60 \%$ \\
\hline
\end{tabular}

Table 2 Estimated energy-cost savings from DCV (Meier 1998 and Mansson 1994)

\subsection{Summary and Conclusions}

This literature review has described the research into the application of $\mathrm{CO}_{2}$-based DCV. It has covered case studies conducted in the field and through computer simulation, research on sensors, and discussions of the application of $\mathrm{CO}_{2}$ control. This section summarizes a number of findings of the literature review and identifies research needs. Table 3 summarizes the literature reviewed in terms of the type of report and topics addressed.

There is fairly wide consensus on the best applications for $\mathrm{CO}_{2}$ control. Most discussions of $\mathrm{CO}_{2}$-based DCV mention the following building types as good candidates: public buildings such as cinemas, theaters and auditoria, educational facilities such as classrooms and lecture halls, meeting rooms, and retail and restaurant establishments. However, it is interesting to note that most of the case studies have investigated office buildings. As presented by Davidge (1991), the following building features correspond to situations where $\mathrm{CO}_{2}$-based DCV are most likely to be effective:

- the existence of unpredictable variations in occupancy

- a building and climate where heating or cooling is required for most of the year

- low pollutant emissions from non-occupant sources.

There have been a number of valuable demonstration projects in real buildings, and many of these have shown significant energy savings through the use of $\mathrm{CO}_{2}$ control. However, several cases exist where the indoor $\mathrm{CO}_{2}$ concentration was rarely high enough for the outdoor air intake dampers to open, suggesting a mismatch between building occupancy, ventilation rates, and control algorithms and setpoints. A significant shortcoming of several of the field tests, as well as of the computer simulation studies, was the inclusion of little or no description of the $\mathrm{CO}_{2}$ sensors or control algorithm investigated in the study. These omissions make it difficult to evaluate which approaches work best and under what circumstances. 
While $\mathrm{CO}_{2}$ DCV can control occupant-generated contaminants effectively, it may not control contaminants with non-occupant sources as well. The control of such non-occupant sources, such as some building materials and outdoor air pollution, is a difficult issue because one cannot engineer for these sources unless their source strengths and indoor concentration limits are known. However, this information is not readily available for most contaminants and sources. A practical solution is to maintain a base ventilation rate at all times, which can be proportional to floor area. A morning purge with outdoor air may also be a good strategy for controlling the buildup of these contaminants over night, and it may be equally applicable to non-DCV systems. An outdoor air purge cycle during the day is another option for controlling non-occupant sources.

The research on sensors indicates that currently available technology is adequate for use in these systems. Some questions have been raised regarding calibration frequency, drift, and temperature effects but new calibration methods have been developed to address these concerns. There is still some debate regarding sensor location, in particular whether to use a single sensor centrally located in the system return or multiple sensors located in the returns for whole floors or in critical spaces, such as conference rooms. Whenever a central location is suggested, the issue of variability among spaces is almost always mentioned. Using a lower setpoint with a central sensor is often suggested as one means of dealing with the variability issue.

A number of needs for more research and information were identified in this literature review. For example, more system-specific guidance on application of $\mathrm{CO}_{2}$-based $\mathrm{DCV}$ is needed. This guidance should be based on system type, zoning, and expected variations in occupancy patterns among the zones. The factors that impact energy savings and other performance issues are becoming better understood, but more sensitivity analysis would be helpful. As mentioned in the literature review, it would still be extremely useful to investigate more $\mathrm{CO}_{2}$-based DCV installations and document them in terms of design and performance. Another issue meriting attention are the positive benefits of using $\mathrm{CO}_{2}$-based DCV to maintain ventilation rates at design levels that help to guarantee sufficient ventilation to occupants, as opposed to its use to using $\mathrm{CO}_{2}$ control to reduce ventilation rates. 


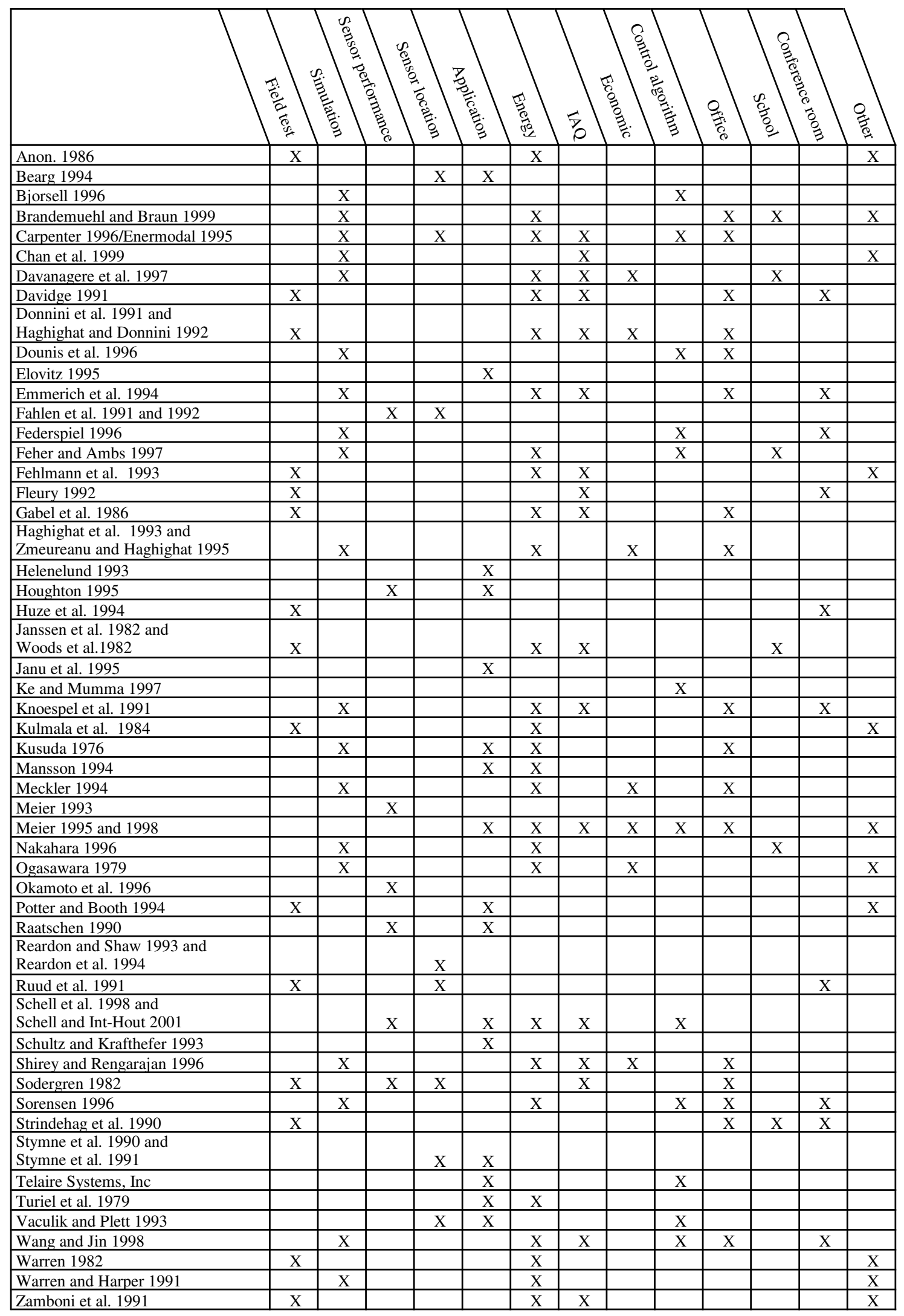

Table 3 Summary of Literature Review 


\section{TECHNOLOGY UPDATE: SENSORS}

The only technologies unique to the application of carbon dioxide demand controlled ventilation are the $\mathrm{CO}_{2}$ sensors themselves. The remaining control hardware and software (including algorithms) are common with other HVAC control applications. This section covers only the $\mathrm{CO}_{2}$ sensors, describing the available technology and some of the relevant performance issues.

Most major HVAC equipment manufacturers offer $\mathrm{CO}_{2}$ demand controlled ventilation as an option, though some highlight its use more than others. However, their application literature does not generally focus on the $\mathrm{CO}_{2}$ sensing technology. Presumably these HVAC manufacturers are using sensors manufactured by other firms.

Sensor manufacturers are definitely promoting the use of $\mathrm{CO}_{2} \mathrm{DCV}$ and several of them provide a good deal of technical information on the performance and application of their products. However, there has not been a great deal of information published on $\mathrm{CO}_{2}$ sensing for control. A recent article by Schell and Int-Hout (2001) provides a brief description of the sensing technology. In addition, the International Energy Agency effort (Annex 18) that studied demand control ventilation in general did perform limited testing of $\mathrm{CO}_{2}$ sensors (Fahlen et al. 1992).

There are basically two types of $\mathrm{CO}_{2}$ sensors used for ventilation control, photometric and photoacoustic. Photometric sensors contain a light source that emits in the infrared range and an optical filter that ensures only wavelengths in the absorbing spectrum of $\mathrm{CO}_{2}$ enter the cell containing the air sample. A photodetector measures the light intensity at a wavelength that is absorbed by $\mathrm{CO}_{2}$. The higher the $\mathrm{CO}_{2}$ concentration in the sample air, the lower the measured light intensity. Photoacoustic sensors also employ an infrared light source with an optical filter. The $\mathrm{CO}_{2}$ molecules in the cell absorb the infrared energy, which in turn increases the molecular vibration and generates an acoustic field. A microphone picks up this field and converts it to an electronic signal related to the $\mathrm{CO}_{2}$ concentration.

Some of the issues affecting sensor performance include interference from other gases (e.g. water vapor), accuracy and drift. The various sensors on the market address these issues using different strategies. Sensor drift arises due to aging of the light source or particle/dust buildup on the optical components. Some sensors use a second detector tuned to a wavelength that isn't absorbed by $\mathrm{CO}_{2}$ to provide a reference value to correct for sensor drift over time. Another approach is to protect the sensor with a gas permeable membrane to avoid contamination by dust. Photoacoustic sensors are not as sensitive to dirt and dust, but are still subject to aging of the light source. Some sensors check the $\mathrm{CO}_{2}$ level at night when indoor concentrations are expected to drop to outdoors and "self-calibrate" to account for drift.

The IEA Annex 18 sensor testing effort included testing of only two $\mathrm{CO}_{2}$ sensors, one photometric and another photoacoustic (Fahlen et al. 1992). The testing involved sensor response as well as the impacts of temperature, mechanical vibration and electrical noise. While the testing was limited to only two sensors, the study concluded that these sensors showed acceptable performance for control but noted that calibration could be a time consuming process based on the sensor rise times of around $10 \mathrm{~min}$.

Sensor manufacturers are continually working to develop cheaper, more accurate and more stable sensors. Their cost is driven to a large degree by the number of sensors that are manufactured and sold. In 1998, prices ranged from around $\$ 400$ to $\$ 500$ per sensor, but have decreased by about $50 \%$ based on continued use (Schell and Int-Hout 2001). This trend is likely to continue as their use expands further. 


\section{STANDARDS AND REGULATORY CONTEXT}

Carbon dioxide demand controlled ventilation clearly must be applied in a manner that is consistent with the relevant building codes and standards. This section discusses the standards and regulatory context relevant to $\mathrm{CO}_{2} \mathrm{DCV}$, specifically ASHRAE Standard 62 and the California Energy Efficiency Standards.

\section{ASHRAE Standard 62}

Before discussing $\mathrm{CO}_{2} \mathrm{DCV}$ in the context of Standard 62, it is appropriate to address some confusion that exists regarding the standard and indoor $\mathrm{CO}_{2}$ levels. For example, a common misunderstanding exists that if indoor carbon dioxide concentrations in a building are maintained below $1800 \mathrm{mg} / \mathrm{m}^{3}$ (1000 ppm(v)) or within $1260 \mathrm{mg} / \mathrm{m}^{3}$ (700 ppm(v)) of outdoors, then the building is in compliance with ASHRAE Standard 62. ASHRAE Standard 62 contains two paths to compliance, the Ventilation Rate Procedure and the Indoor Air Quality Procedure. The Ventilation Rate Procedure requires that one determine the design ventilation rate of a building based on the space-use in the building, the number of occupants and the outdoor air requirements for various space-use categories in Table 2 of the standard. The Ventilation Rate Procedure also contains requirements for contaminant levels in the outdoor air and that no unusual contaminants or sources exist. While compliance with the Ventilation Rate Procedure is likely to maintain indoor carbon dioxide concentrations within $1260 \mathrm{mg} / \mathrm{m}^{3}(700 \mathrm{ppm}(\mathrm{v}))$ of outdoors (corresponding to about $1800 \mathrm{mg} / \mathrm{m}^{3}$ (1000 ppm(v)) for typical outdoor $\mathrm{CO}_{2}$ concentrations), the other requirements of the procedure must also be met to achieve compliance with the entire standard.

The Indoor Air Quality Procedure of the 1989 version of the standard contained a guideline for indoor carbon dioxide concentrations of $1800 \mathrm{mg} / \mathrm{m}^{3}(1000 \mathrm{ppm}(\mathrm{v}))$, but that guideline was removed in the 1999 version. However, complying with this guideline alone was never sufficient for achieving compliance with the standard. In addition to this carbon dioxide guideline, the IAQ Procedure also contained and still contains limits for four other contaminants of predominantly outdoor origin in Table 1 of the standard and three others in Table 3. In addition, one also must to keep all other known contaminants of concern below specific levels. The Indoor Air Quality Procedure also contains a requirement for the subjective evaluation of the acceptability of the level of those contaminants for which no objective measures of acceptability are available. While it may not be clear how one identifies these contaminants of concern and the associated levels of acceptability, it is clear that simply maintaining carbon dioxide below $1800 \mathrm{mg} / \mathrm{m}^{3}$ $(1000 \mathrm{ppm}(\mathrm{v}))$ is not sufficient.

That being said, let us now review how the standard does address the issue of $\mathrm{CO}_{2}$ demand controlled ventilation. Section 6 of this standard, Procedures, provides the means of designing building ventilation systems for achieving acceptable indoor air quality. Two procedures exist for doing so, the Ventilation Rate Procedure and the Indoor Air Quality (IAQ) Procedure. The former prescribes minimum outdoor air ventilation requirements for a number of different space types, expressed as $(\mathrm{L} / \mathrm{s}) \mathrm{cfm}$ per person, $\left(\mathrm{L} / \mathrm{s}-\mathrm{m}^{2}\right) \mathrm{cfm} / \mathrm{ft}^{2}$ of floor area or $\mathrm{cfm}(\mathrm{L} / \mathrm{s})$ per room, with the units depending on the space type. The standard does not specifically discuss the application of demand-controlled ventilation, however, it is quite logical to apply this approach to spaces where the outdoor air requirement is expressed as $(\mathrm{L} / \mathrm{s}) \mathrm{cfm}$ per person. If carbon dioxide, or some other demand control approach, is employed as a "people counter," then the outdoor air could be varied in response to changes in occupancy. In fact, ASHRAE has issued interpretation \#33 of Standard 62-1999 (also referred to as interpretation \#27 of Standard 621989) that allows this application. The interpretation allows the use of $\mathrm{CO}_{2}-\mathrm{DCV}$ as long as other 
provisions of the standard (specifically requirements related to intermittent occupancy) have not been used to reduce the estimated occupancy, $\mathrm{CO}_{2}$ is not being removed by other methods such as air cleaning, and a control algorithm is used to achieve the rates in Table 2 of the standard. The interpretation does specifically allow for a number of different control algorithms, including " make or break" (on/off), proportional, proportional-integral, and proportional-integralderivative, and specifically mentions the use of the difference between indoor and outdoor $\mathrm{CO}_{2}$ levels in these controls. However, the interpretation notes "good practice and the rationale on which the ventilation rates in Table 2 are based, indicates the need for a non-zero base ventilation rate to handle non-occupant sources whenever the space is occupied." Therefore, some residual ventilation needs to be provided to handle non-occupant contaminant sources, but neither the standard nor the interpretation indicates how much ventilation that is.

The IAQ Procedure is a performance-based method for providing acceptable IAQ in which the design is based on the control of certain "contaminants of concern" to specified acceptable levels. The standard neither identifies the contaminants on which to base the design nor the acceptable levels; that is up to the user of the standard. Carbon dioxide DCV could be one means of implementing the IAQ Procedure, but realistically one would also need to address contaminants that are not generated at rates associated with the number of occupants.

Another aspect of the standard that is relevant to $\mathrm{CO}_{2}-\mathrm{DCV}$ is the indoor $\mathrm{CO}_{2}$ guideline that was in the 1989 version of the standard. Table 3 of the standard (both the 1989 and 1999 versions) contains guidelines for selected air contaminants for potential use with the IAQ Procedure. The 1989 version of Table 3 included a limit of $1800 \mathrm{mg} / \mathrm{m}^{3}$ (1000 ppm(v)) for indoor $\mathrm{CO}_{2}$, which was the subject of much confusion. Specifically, some readers of the standard interpreted this guideline as indicating that indoor $\mathrm{CO}_{2}$ levels about $1800 \mathrm{mg} / \mathrm{m}^{3}(1000 \mathrm{ppm}(\mathrm{v}))$ were a health hazard. In fact, this guideline was based on the association with indoor $\mathrm{CO}_{2}$ levels with the level of odor due to human bioeffluents. Since then, the approval of Addendum $62 \mathrm{f}$ to the standard in 1999 and its incorporation in Standard 62-1999 removed the $1800 \mathrm{mg} / \mathrm{m}^{3}$ (1000 ppm(v)) $\mathrm{CO}_{2}$ guideline and replaced it with the actual contaminant of interest, i.e., human bioeffluents. Additional changes to Appendix D of the standard explained that odor levels from human bioeffluents were likely to be acceptable to the majority of visitors entering a space if the indoor $\mathrm{CO}_{2}$ level were no more than $1260 \mathrm{mg} / \mathrm{m}^{3}$ (700 ppm(v)) above outdoors.

\section{California's Energy Efficiency Standards for Residential and Nonresidential Buildings}

The CEC standards (1999), often referred to as Title 24, discuss demand-controlled ventilation under Section 121 - Requirements for Ventilation. In addition to providing minimum outdoor air ventilation rates, section 121 (c) discusses operation and control of outdoor air. An exception to the requirement that the specified outdoor air rates shall be supplied whenever the space is occupied states that the outdoor air rate may be reduced to $0.76 \mathrm{~L} / \mathrm{s}-\mathrm{m}^{2}\left(0.15 \mathrm{cfm} / \mathrm{ft}^{2}\right)$ if the system is controlled by an approved demand controlled ventilation device and in the case of $\mathrm{CO}_{2}$ control, the indoor $\mathrm{CO}_{2}$ level is limited to no more than $1440 \mathrm{mg} / \mathrm{m}^{3}(800 \mathrm{ppm}(\mathrm{v}))$ while the space is occupied. The basis for this limit is not provided in the document, but it should be noted that an indoor $\mathrm{CO}_{2}$ level of $1440 \mathrm{mg} / \mathrm{m}^{3}$ (800 ppm(v)) corresponds to about $11.5 \mathrm{~L} / \mathrm{s}(23 \mathrm{cfm})$ per person of outdoor air under steady state conditions.

These standards were revised in January 2001 in a document containing emergency regulations, referred to as $\mathrm{AB} 970$ (CEC 2001a). The requirements for $\mathrm{CO}_{2}$ demand-controlled ventilation remained largely the same as the 1999 standards, with a few exceptions. One significant change is that demand control ventilation is required for spaces with fixed seating and occupant densities less than or equal to about $9 \mathrm{~m}^{2}\left(10 \mathrm{ft}^{2}\right)$ per person and for spaces with outdoor air capacities 
greater than or equal to $1400 \mathrm{~L} / \mathrm{s}(3000 \mathrm{cfm})$. However, note that these requirements are for any form of demand control that reduce outdoor air intake based on occupancy, not just those based on $\mathrm{CO}_{2}$ sensing. While the standard is not specific, such control could be based on timers, occupancy sensors and other approaches. When the control device is based on indoor $\mathrm{CO}_{2}$ levels, the emergency standards still require that the indoor $\mathrm{CO}_{2}$ levels not exceed $1440 \mathrm{mg} / \mathrm{m}^{3}$ (800 ppm(v)) when the space is occupied. As noted above, this $\mathrm{CO}_{2}$ level corresponds to an outdoor air ventilation rate of $11.5 \mathrm{~L} / \mathrm{s}(23 \mathrm{cfm})$ per person at steady-state. In addition, the 2001 standard requires a sensor in the space or in a return airstream from the space, with one sensor for every $2300 \mathrm{~m}^{2}\left(25,000 \mathrm{ft}^{2}\right)$ of habitable space.

Revisions to the 2001 emergency standards (CEC 2001b) were recently issued for review prior to their adoption on April 4, 2001. These proposed revisions add an exception to the $1440 \mathrm{mg} / \mathrm{m}^{3}$ $(800 \mathrm{ppm}(\mathrm{v}))$ if the ventilation rate is greater than or equal to the rate required by the standard.

The current versions of ASHRAE Standard 62-1999 and California's Title 24 Energy Efficiency Standards both allow the use of $\mathrm{CO}_{2}$ demand-controlled ventilation. However, neither document provides much application guidance or specific requirements in several important areas including sensors (number, placement, accuracy, calibration or maintenance), control algorithms and setpoints, or base ventilation rates. To effectively realize the energy saving potential of this technology, such guidance is definitely needed.

\section{SUMMARY}

Carbon dioxide demand controlled ventilation (DCV) attempts to achieve acceptable indoor air quality (IAQ) at reduced energy cost by matching a ventilation system's outdoor airflow rate to the real-time occupancy as indicated by indoor $\mathrm{CO}_{2}$ levels. The potential advantages of $\mathrm{CO}_{2}-$ based DCV are increased ventilation when occupancy is high, a feedback control mechanism to ensure acceptable IAQ and energy savings from decreased ventilation when occupancy is low. While the energy savings potential of this approach has been highlighted in several studies, there are still some important questions related to the implementation of $\mathrm{CO}_{2}$-based DCV. One of the most critical issues is that low $\mathrm{CO}_{2}$ levels alone do not guarantee acceptable IAQ. For example, the concentrations of non-occupant generated pollutants may not be well controlled by such a system, or at least they can become elevated during periods of low occupancy due to decreased ventilation. Also, nonuniformities in air distribution and in building occupancy can present difficulties in locating sensors such that a representative $\mathrm{CO}_{2}$ concentration is measured. While the potential energy savings have been identified in a number of earlier studies, additional study is needed to help designers estimate the actual saving that can be realized in specific situations. In addition, work remains to be done on improving $\mathrm{CO}_{2}$ sensors and in developing application guidance. Future phases of this project will focus on increasing our understanding of the energy savings potential and in developing improved application guidance. 


\section{ACKNOWLEDGEMENTS}

This report was supported by the California Energy Commission through the Architectural Energy Corporation. The authors acknowledge the contributions of Vern Smith of the Architectural Energy Corporation, James Braun of Purdue University, William Healy of NIST and Amy Musser of the University of Nebraska. 


\section{REFERENCES}

ACGIH. 2001. 2001 Threshold Limit Values (TLVs) for Chemical Substances and Physical Agents and Biological Exposure Indices (BEIs). American Conference of Governmental Industrial Hygienists.

Anon. 1986. Ventilation Control by Measurement of Carbon Dioxide Levels in Public Entertainment Buildings. Energy Technology Support Unit AERE Harwell, Oxfordshire.

Apte, M.G., W.J. Fisk and J.M. Daisey. 2000. Associations Between Indoor $\mathrm{CO}_{2}$ Concentrations and Sick Building Syndrome Symptoms in US Office Buildings: An Analysis of the 1994-1996 BASE Study Data. Indoor Air 10 (4): 246-257.

ASHRAE. 1997. Fundamentals Handbook, Chapter 8 Thermal Comfort. American Society of Heating, Refrigerating and Air-Conditioning Engineers, Inc.

ASHRAE. 1989. Standard 62-1989, Ventilation for Acceptable Indoor Air Quality. American Society of Heating, Refrigerating and Air-Conditioning Engineers, Inc., Atlanta, GA.,

ASHRAE. 1999. Standard 62-1999, Ventilation for Acceptable Indoor Air Quality. American Society of Heating, Refrigerating and Air-Conditioning Engineers, Inc., Atlanta, GA.,

ASTM. 1998. Standard Guide for Using Indoor Carbon Dioxide Concentrations to Evaluate Indoor Air Quality and Ventilation. American Society for Testing and Materials, West Conshohoken, PA, D6245-98.

Axley, J. 1988. Progress Toward a General Analytical Method for Predicting Indoor Air Pollution in Buildings: Indoor Air Quality Modeling Phase III Report. Gaithersburg, Maryland: National Bureau of Standards, NBSIR 88-3814.

Bearg, D.W. 1994. Second Generation Demand-Controlled Ventilation Systems. Proceedings of ASHRAE IAQ 94: 169-174.

Bell, S.J. and B. Khati. 1983. Indoor Air Quality in Office Buildings. Occupational Health in Ontario. 4: 103-118.

Berg-Munch, B., G. Clausen and P.O. Fanger. 1986. Ventilation Requirements for the Control of Body Odor in Spaces Occupied by Women. Environment International 12: 195-199.

Bjorsell, N. 1996. Control Strategies for Demand Controlled Ventilating Systems. Proceedings of Roomvent '96.

Brandemuehl, M.J. and J.E. Braun. 1999. The Impact of Demand-Controlled and Economizer Ventilation Strategies on Energy Use in Buildings. ASHRAE Transactions 105 (2): 39-50.

Bright, P.D., M.J. Mader, D.R. Carpenter and I.Z. Hermon-Cruz. 1992. Guide for Indoor Air Quality Surveys. Armstrong Laboratory, Brooks Air Force Base, Texas, AL-TR-1992-0016.

California Energy Commission. 1999. Energy Efficiency Standards for Residential and Nonresidential Buildings, P400-98-001.

California Energy Commission. 2001a. AB970 Energy Efficiency Standards for Residential and Nonresidential Buildings, P400-01-001.

California Energy Commission. 2001b. AB970 Energy Efficiency Standards for Residential and Nonresidential Buildings, P400-01-009. 
Cain, W.S., B.P. Leaderer, R. Isseroff, L.G. Berglund, R.J. Huey, E.D. Lipsitt and D. Perlman. 1983. Ventilation Requirements in Buildings - I. Control of Occupancy Odor and Tobacco Smoke Odor. Atmosphere Environment. 17: 1183-1197.

Carpenter, S.C. 1996. Energy and IAQ Impacts of $\mathrm{CO}_{2}$-Based Demand-Controlled Ventilation. ASHRAE Transactions 102 (2): 80-88.

CEC. 1992. Guidelines for Ventilation Requirements in buildings. Report No. 11, European Concerted Action Indoor Air Quality \& Its Impact on Man. Commission of the European Communities, Brussels,

Chan, G.Y., C.Y. Chao, D.C. Lee, S.W. Chan, and H. Lau. 1999. Development of a Demand Control Strategy in Buildings using Radon and Carbon Dioxide Levels. Proceedings of Indoor Air 99 1:48-53.

Clarke, J. and D. McLean. 1986. ABACUS. E.S.P. Documentation - A Plant and Energy Simulation System. Strathclyde University.

Davanagere, B.S., Shirey, D.B., Rengarajan, K., and F. Colacino. 1997. Mitigating the Impacts of ASHRAE Standard 62-1989 on Florida Schools. ASHRAE Transactions 103 (1): 241-258.

Davidge, B. 1991. Demand Controlled Ventilation Systems in Office Buildings. Proceedings of the 12th AIVC Conference Air Movement \& Ventilation Control within Buildings: 157-171. Coventry, Great Britain: Air Infiltration and Ventilation Centre.

Di Giacomo, S.M. 1999. DCV: History, Theory, Myths. Engineered Systems, February 1999.

Donnini, G., F. Haghighat, and V.H. Hguyen. 1991. Ventilation Control of Indoor Air Quality, Thermal Comfort, and Energy Conservation by $\mathrm{CO}_{2}$ Measurement. Proceedings of the 12th AIVC Conference Air Movement \& Ventilation Control within Building: 311-331.

Dounis, A.I., M. Bruant, G. Guarracino, and P. Michel. 1996. Indoor Air-Quality Control by a Fuzzy-Reasoning Machine in Naturally Ventilated Buildings. Applied Energy; 1:11-28.

Elovitz, D.M. 1995. Minimum Outside Air Control Methods for VAV Systems. ASHRAE Transactions 101 (2): 613-618.

Emmerich, S.J., J.W. Mitchell, and W.A. Beckman. 1994. Demand-Controlled Ventilation in a Multi-Zone Office Building. Indoor Environment 3: 331-340.

Emmerich, S.J. and A.K. Persily. 1997. Literature Review on $\mathrm{CO}_{2}$-Based Demand-Controlled Ventilation. ASHRAE Transactions 103 (2): 229-243.

Enermodal. 1995. An Evaluation of the Effect of $\mathrm{CO}_{2}$-Based Demand-Controlled Ventilation Strategies on Energy Use and Occupant-Source Contaminant Concentrations. ASHRAE Research Project 740-TRP. Waterloo, Ontario: Enermodal Engineering Limited.

Enermodal. 1990. Enerpass Version 3.0. Waterloo, Ontario: Enermodal Engineering Limited.

EPA. 1991. Introduction to Indoor Quality. A Reference Manual. U.S. Environmental Protection Agency, U.S. Public Health Service, National Environmental Health Association, EPA/400/391/003.

EPA. 1999. Exposure Factors Handbook. U.S. Environmental Protection Agency, EPA/600/C99/001. 
Fahlen, P., H. Andersson, and S. Ruud. 1991. Demand Controlled Ventilation - Evaluation of Commercially Available Sensors. Proceedings in the 12th AIVC Conference Air Movement \& Ventilation Control within Buildings: 201-216.

Fahlen, P., H. Andersson and S. Ruud. 1992. Demand Controlled Ventilating Systems Sensor Tests. Swedish National Testing and Research Institute, Boras, Sweden, SP Report 1992:13.

Fanger, P.O. and B. Berg-Munch. 1983. Ventilation and Body Odor. Engineering Foundation Conference on Management of Atmospheres in Tightly Enclosed Spaces, Santa Barbara, CA. 4550 .

Fanger, P.O. 1988. Introduction of the Olf and Decipol Units to Quantify Air Pollution Perceived by Humans Indoors and Outdoors. Energy and Buildings. 12: 1-6.

Federspiel, C.C. 1996. On-Demand Ventilation Control: A New Approach to DemandControlled Ventilation. Proceedings of Indoor Air '96.

Feher, T.R. and L.L. Ambs. 1997. The Use of $\mathrm{CO}_{2}$ Readings with Fixed Ventilation to Predict Energy Savings with Demand-Controlled Ventilation. Proceedings of Healthy Buildings/IAQ '97.

Fehlmann, J., H. Wanner, and M. Zamboni. 1993. Indoor Air Quality and Energy Consumption with Demand Controlled Ventilation in an Auditorium. Proceedings of the 6th International Conference on Indoor Air Quality and Climate. Vol. 5: 45-50.

Fleury, B. 1992. Demand Controlled Ventilation: A Case Study. Proceedings of the 13th AIVC Conference Ventilation for Energy Efficiency and Optimum Indoor Air Quality: 343-346.

Gabel, S. D., J.E. Janssen, J. O. Christoffel, and S. E. Scarborough. 1986. Carbon Dioxide-Based Ventilation Control System Demonstration. U. S. Department of Energy, DE-AC79-84BP15102.

Haghighat, F. and G. Donnini. 1992. IAQ and Energy-Management by Demand Controlled Ventilation. Environmental Technology. 13: 351-359.

Haghighat, F., R. Zmeureanu, and G. Donnini. 1993. Energy Savings in Building by Demand Controlled Ventilation System. Proceedings of the 6th International Conference on Indoor Air Quality and Climate. 5: 51-56.

Helenelund, C. 1993. Future of DCV - What is Economically Feasible? Proceedings of Air the 6th International Conference on Indoor Air Quality and Climate. 5: 57-62.

Houghton, D. 1995. Demand-Controlled Ventilation: Teaching Buildings to Breathe. Boulder, CO: E. Source, Inc, TU-95-10.

Huze, M.H., Meneboo, F., and J.B. Hoffmann. 1994. Air quality sensors: a field evaluation. Proceedings of Roomvent 94 2:491-501.

Iwashita, G., K. Kimura, S. Tanabe, S. Yoshizawa and K. Ikeda. 1990. Indoor Air Quality Assessment Based on Human Olfactory Sensation. Journal of Architectural Planning and Environmental Engineering. 410: 9-19.

Janssen, J. E., T.J. Hill, J.E. Woods, and E.A.B. Maldonado. 1982. Ventilation for Control of Indoor Air Quality: A Case Study. Environment International. 8: 487-496.

Janu, G.J., J.D. Wenger, and C.G. Nesler. 1995. Strategies for Outdoor Airflow Control from a Systems Perspective. ASHRAE Transactions 101 (2): 631-643. 
Ke, Y.-P. and S.A. Mumma. 1997. Using Carbon Dioxide Measurements to Determine Occupancy for Ventilation Controls. ASHRAE Transactions 103 (2): 365-374.

Klein S. 1994. TRNSYS, A Transient System Simulation Program, Version 14.1 Users Manual. University of Wisconsin-Madison: Solar Energy Laboratory.

Knoespel P, J. Mitchell, and W. Beckman. 1991. Macroscopic Model of Indoor Air Quality and Automatic Control of Ventilation Airflow. ASHRAE Transactions 97 (2): 1020-1030.

Kulmala, V., A. Salminen, G. Graeffe, K. Janka, J. Keskinen, and M. Rajala. 1984. Long-Term Monitoring of Indoor Air Quality and Controlled Ventilation in Public Buildings. Proceedings of the 3rd International Conference on Indoor Air Quality and Climate. Vol. 5: 435-441.

Kusuda, T. 1976. Control of Ventilation to Conserve Energy While Maintaining Acceptable Indoor Air Quality. ASHRAE Transactions 82 (1): 1169-1181.

Mansson, L. 1989. Annex 18 Demand Controlled Ventilating Systems. Proceedings of the 10th AIVC Conference Progress and Trends in Air Infiltration Research: 25-43

Mansson, L. 1994. Demand Controlled Ventilation Systems in Non-industrial Buildings. Proceedings of the European Conference on Energy Performance and Indoor Climate in Buildings.

Meckler, M. 1994. Demand-Control Ventilation Strategies for Acceptable IAQ.

Heating/Piping/Air Conditioning. May: 71-74.

Meier, S. 1993. Mixed-Gas or $\mathrm{CO}_{2}$ Sensors as a Reference Variable for Demand-Controlled Ventilation. Proceedings of the 6th International Conference on Indoor Air Quality and Climate. Vol. 5: 85-90.

Meier, S. 1995. Demand-Based Ventilation: Indoor Comfort at Lower Cost. Proceedings of Healthy Buildings '95, 1743-1750.

Meier S. 1998. Demand-Controlled Ventilation - Requirements and Control Strategies. Proceedings of Roomvent '98.

Nakahara, N. 1996. How to Design and Evaluate the HVAC for Better Indoor Air Quality with Sufficient Energy Saving. Proceedings of Indoor Air '96. Vol. 2: 3-15

NIOSH. 1987. A Guide to Safety in Confined Spaces. Cincinnati, OH: National Institute of Occupational Safety and Health, DHHS Publication No. 87-113.

Ogasawara, S., H. Taniguchi, and C. Sukehira. 1979. Effect of Energy Conservation by Controlled Ventilation: Case Study in a Department Store. Energy and Buildings 2: 3-8.

Okamoto, S., Muramatsu, S., Jeng, D.Y., Hadano, H., Nagawa, Y., and H. Futata. 1996. The Exploration of the Use of a Carbon Dioxide Sensor for Indoor Air Control. Proceedings of Indoor Air '96. Vol. 3: 333-338.

Persily, A.K. and W. S. Dols. 1990. The Relation of $\mathrm{CO}_{2}$ Concentration to Office Building Ventilation. Air Change Rate and Airtightness in Buildings, ASTM STP 1067: 77-92.

Persily, A.K. 1993. Ventilation, Carbon Dioxide and ASHRAE Standard 62-1989. ASHRAE Journal. 35: 40-44.

Persily, A.K. 1997. Evaluating Building IAQ and Ventilation with Indoor Carbon Dioxide. ASHRAE Transactions. 103 (2): 193-204. 
Potter, I.N. and W.B. Booth. 1994. $\mathrm{CO}_{2}$ Controlled Mechanical Ventilated Systems. Technical

Note. Bracknell, Berkshire: Building Services Research and Information Association, TN 12/94.

Raatschen, W., ed. 1990. Demand Controlled Ventilating System. State of the Art Review. Stockholm, Sweden: Swedish Council for Building Research, D9.

Rajhans, G.S. 1983. Indoor Air Quality and $\mathrm{CO}_{2}$ Levels. Occupational Health in Ontario. 4: 160167.

Rasmussen, C., G.H. Clausen, B. Berg-Munch and P.O. Fanger. 1985. The Influence of Human Activity on Ventilation Requirements for the Control of Body Odor. CLIMA 2000. Vol. 4: 357 362.

Reardon, J.T. and C.Y. Shaw. 1993. Carbon Dioxide Concentrations and Minimum Air Change Rates in a High-Rise Office Building. Indoor Environment 2: 337-343.

Reardon, J.T., C.Y. Shaw, and F. Vaculik. 1994. Air Change Rates and Carbon Dioxide Concentrations in a High-Rise Office Building. ASHRAE Transactions 100 (2): 1251-1263.

Ruud, S.H., P. Fahlen, and H. Andersson. 1991. Demand Controlled Ventilation - Full Scale Tests in a Conference Room. Proceedings of the 12th AIVC Conference Air Movement \& Ventilation Control within Buildings: 187-200.

Schell, M.B., S.C. Turner, and R.O. Shim. 1998. Application of $\mathrm{CO}_{2}$-Based Demand-Controlled Ventilation Using ASHRAE Standard 62: Optimizing Energy Use and Ventilation. ASHRAE Transactions 104: 1213-1225.

Schell, M. 2001. Proven Energy Savings with DCV retrofits. HPAC Engineering, February 2001.

Schell, M. and D. Int-Hout. 2001. Demand Control Ventilation Using $\mathrm{CO}_{2}$. ASHRAE Journal. 43 (2): $18-29$.

Schultz, K.J. and B.C. Krafthefer. 1993. $\mathrm{CO}_{2}$-Based Ventilation Control: Choice of $\mathrm{CO}_{2}$ Setpoint. ASHRAE Transactions 99 (1): 1548-1553.

Seppanen, O.A., W.J. Fisk and M. J. Mendell. 1999. Association of Ventilation Rates and $\mathrm{CO}_{2}$ Concentrations with Health and Other Responses in Commercial and Institutional Buildings. Indoor Air. 9 (4): 226-252.

Shirey, D.B. and K. Rengarajan. 1996. Impacts of ASHRAE Standard 62-1989 on Small Florida Offices. ASHRAE Transactions 102 (1): 153-165.

Sodergren, D. 1982. A CO 2 -Controlled Ventilation System. Environment International 8: 483486.

Sorensen, B.R. 1996. Simulation of a Small VAV Plant. Proceedings of Indoor Air '96. Vol. 2: 199-204.

Strindehag, O., L. Norell, and S. Kvarnstrom. 1990. Improved Indoor Air Quality by Supervision of the $\mathrm{CO}_{2}$ Content. Proceedings of the 5th International Conference on Indoor Air Quality and Climate. Vol. 4: 437-441.

Strindehag, O., and L. Norell. 1991. Long Term Experience with Demand-Controlled Ventilation Systems. Proceedings of ASHRAE IAQ 91, Healthy Buildings: 108-110.

Stymne, H., A. Mellin, and M. Sandberg. 1990. Dispersion Pattern of Carbon Dioxide from Human Sources - A Factor to Consider in Demand Controlled Ventilation Systems. Proceedings of the 5th International Conference on Indoor Air Quality and Climate. Vol. 4: 317-322. 
Stymne, H., M. Sandberg, and M. Mattsson. 1991. Dispersion Pattern of Contaminants in a Displacement Ventilated Room - Implications for Demand Control. Proceedings of the 12th AIVC Conference Air Movement \& Ventilation Control within Buildings: 173-189.

Telaire Systems, Inc. n.d. Application Guide for Carbon Dioxide $\left(\mathrm{CO}_{2}\right)$ Measurement \& Control. Goleta, CA.

Turiel, I., C.D. Hollowell, and B.E. Thurston. 1979. Variable Ventilation Control Systems: Saving Energy and Maintaining Indoor Air Quality. Berkeley, CA: Lawrence Berkeley Laboratory. LBL- 9380.

Vaculik, F. and E.G. Plett. 1993. Carbon Dioxide Concentration-Based Ventilation Control. ASHRAE Transactions 99 (1): 1536-1547.

Walton, G. 1989. AIRNET - A Computer Program for Building Airflow Network Modeling. Gaithersburg, MD: National Institute of Standards and Technology, NISTIR 89-4072.

Wang S. and X. Jin. 1998. $\mathrm{CO}_{2}$-Based Occupancy Detection for On-Line Outdoor Air Flow Control. Indoor \& Built Environment; 7:165-181.

Wang S. and X. Jin. 1999. Experimental Validation of $\mathrm{CO}_{2}$-Based Occupancy Detection for Demand-Controlled Ventilation. Indoor \& Built Environment; 8:377-391.

Warren, B.F. 1982. Energy Savings in Buildings by Control of Ventilation as a Function of Indoor Carbon Dioxide Concentration. Building Services Engineering Research \& Technology 3 (1): 4-12.

Warren, B.F. and N.C. Harper. 1991. Demand Controlled Ventilation by Room $\mathrm{CO}_{2}$ Concentration: A Comparison of Simulated Energy Savings in an Auditorium Space. Energy and Buildings 17: 87-96.

Woods, J.E., G. Winakor, E.A.B. Maldonado, and S. Kipp. 1982. Subjective and Objective Evaluation of a $\mathrm{CO}_{2}$-Controlled Variable Ventilation System. ASHRAE Transactions 88 (1): 1385-1393.

Wright, G. 1997. DCV expands options for improving IAQ. Building Design \& Construction, January 1997.

Zamboni, M., O. Berchtold, C. Filleux, J. Fehlmann, and F. Drangsholt. 1991. Demand Controlled Ventilation - An Application to Auditoria. Proceedings of the 12th AIVC Conference Air Movement \& Ventilation Control within Buildings: 143-155.

Zmeureanu, R., and F. Haghighat. 1995. Computer Simulation of the Impact of $\mathrm{CO}_{2}$-based Ventilation Control. Proceeding of Building Simulation '95: 206-212. 


\section{Appendix A: CEC RFP Issues}

The California Energy Commission (CEC) Public Interest Energy Research (PIER) Request for Proposals for the Buildings Energy Efficiency Program Area identified four key issues of concern. These four issues identify energy problems facing buildings in California and present opportunities to have a significant positive impact. This appendix discusses the relationship of the application of $\mathrm{CO}_{2}$-based DCV systems to the four key issues based on information in this report.

Issue \#1 Energy consumption is rapidly increasing in hotter, inland areas as new building construction increases in these areas.

A key intent of $\mathrm{CO}_{2}$-based DCV systems is the reduction of energy consumed to cool and heat ventilation air in buildings. As discussed in the review of case studies in this report, they are capable of achieving such reductions for many building types in a variety of climates. Fortuitously, DCV systems may be very well suited to reducing energy consumption in the hotter, inland areas of California as evidenced by a recent simulation study (Brandemuehl and Braun 1999).

Brandemuehl and Braun simulated the energy impacts of DCV systems and economizers for four building types (office, retail, school, and restaurant) in a variety of locations including Sacramento. They reported potential electrical energy savings of $17 \%$ for the restaurant in Sacramento with both a DCV system and an economizer. Equal savings were due to the DCV system and the economizer. For the other building types in Sacramento, the combined DCV and economizer systems reduced electrical energy consumption by $10 \%$ for the office, $19 \%$ for the retail, and $18 \%$ for the school. Since Brandemuehl and Braun and others have reported larger potential savings for humid locations and hotter locations, a DCV system with an economizer is likely to save even more electrical energy in locations such as Fresno and Palm Springs, climates combining warm weather and high humidity levels. The use of carefully scheduled purge ventilation with DCV could also increase energy savings by reducing ventilation during the hottest times of the day.

Issue \#2 Development of energy efficient products and services needs to adequately consider non-energy benefits, such as comfort, productivity, durability, and decreased maintenance.

Since $\mathrm{CO}_{2}$-based DCV systems directly affect building ventilation rates, the potential exists to have a significant impact on occupant comfort and productivity. That impact could be either positive or negative depending on the DCV system design, installation, operation and maintenance. $\mathrm{CO}_{2}$-based DCV systems can indeed have a positive impact on IAQ that is not always considered, when building zones are occupied by more people than the number on which the ventilation system design is based. At such times, a DCV system will result in improved IAQ by providing an appropriate amount of ventilation to the space. Additionally, ventilation systems may operate with lower ventilation effectiveness than the design criteria. Again, a DCV system can increase ventilation rates in such situations. While it is not possible to estimate potential impacts on productivity for any given building, Fisk and Rosenfeld (1997) have estimated that nationwide impacts of better indoor environments are in the billions of dollars.

Since DCV systems adjust ventilation rates based on measured concentrations of $\mathrm{CO}_{2}$ generated by building occupants, they do not directly guarantee satisfactory indoor air quality (IAQ) due to the presence of non-occupant generated contaminants. This issue results in a concern by some that DCV could result in poor IAQ, which could negatively impact comfort and productivity. Certain steps need to be taken to avoid the occurrence of such a negative impact. The most 
fundamental step is to implement the same good IAQ practices that should be applied to all commercial buildings. These practices include reduction of contaminant sources, proper installation and maintenance of equipment, etc. Additional steps that should be taken for DCV systems include appropriate selection of control algorithms and setpoints, thoughtful consideration of expected contaminant sources, establishment of minimum base and/or purge ventilation rates and schedules, system commissioning, and proper maintenance and calibration of $\mathrm{CO}_{2}$ sensors.

Issue \#3 Building design, construction, and operation of energy-related features can affect public health and safety.

The above discussion addressing Issue \#2 also applies to public health. $\mathrm{CO}_{2}$-based DCV systems could have either a negative or positive impact on public health, and therefore care needs to be taken in their application. In addition, DCV can have a very positive impact in lessening the moisture load in non-residential buildings in humid climates. Since most of the moisture load for many non-residential buildings is brought into a building through ventilation, reducing excess ventilation during times of reduced building occupancy can reduce this moisture load. This reduction in moisture load can save energy and money by eliminating the need for special equipment.

Issue \#4 Investments in energy efficiency can affect building and housing affordability and value, and the state's economy.

As discussed in response to Issue \#1, $\mathrm{CO}_{2}$-based DCV systems can reduce building heating and cooling energy use and, therefore, reduce operating costs to improve building affordability and value. However, these potential savings will vary widely depending on building type, climate, occupancy density and patterns, other HVAC system characteristics, and other factors. While knowledge of these important parameters is growing, more work is needed to identify the best opportunities for energy savings. No significant impacts are expected on the energy-related costs of construction.

\section{$\underline{\text { References }}$}

Brandemuehl, M.J. and J.E. Braun. The Impact of Demand-Controlled and Economizer Ventilation Strategies on Energy Use in Buildings (1999) ASHRAE Transactions 105 (2): 39-50.

Fisk, W.J. and A.H. Rosenfeld. Estimates of Improved Productivity and Health from Better Indoor Environments (1997) Indoor Air 1997; 7:158-172. 


\section{Appendix B: Preliminary Application Guidance}

The intent of this section is to summarize the currently available guidance on the application of $\mathrm{CO}_{2}$-based DCV while acknowledging that significant knowledge gaps still remain. This summary is based on guidance in various publications including lessons learned from published case studies. Future phases of this study are intended to fill in many of these knowledge gaps and to develop more definitive guidance. Furthermore, it is not the intent of this section to describe a system that meets ASHRAE Standard 62 or any other ventilation standard.

\section{Target buildings}

The intent of a $\mathrm{CO}_{2}$-based DCV is to save cooling, heating, and fan energy use compared to ventilation at a constant rate based on design occupancy, while assuring adequate ventilation rates for IAQ control. While $\mathrm{CO}_{2}$-based DCV systems are likely to save at least some energy for nearly all buildings and climates, the amount of energy saved can vary dramatically depending on the climate, occupancy, operating hours, and other building and HVAC system features. The greatest energy savings are likely to occur in buildings with large heating loads or large cooling loads that have dense occupancies that vary unpredictably. This section highlights circumstances, specifically buildings and spaces, where $\mathrm{CO}_{2}$ DCV appears to make the most sense.

\section{Good candidates}

Building or spaces where the occupants are likely to be the only significant source of $\mathrm{CO}_{2}$. Buildings or spaces with dense, unpredictably variable occupancies.

Buildings or spaces in climates that have significant heating or cooling loads.

Variably occupied spaces that have independent outdoor air supply capability such as a conference rooms within buildings in which the building as a whole may not be a good candidate.

\section{Poor candidates}

Buildings or spaces where ventilation requirements are dominated by non-occupant generated pollutants.

Buildings or spaces with significant sources of $\mathrm{CO}_{2}$ other than occupants. Using $\mathrm{CO}_{2}$ as the control variable in such applications will not necessarily result in unacceptable IAQ but rather could cause excessive ventilation rates. In such cases, it may be possible to control the ventilation rate based on another measured parameter.

Buildings or spaces with any $\mathrm{CO}_{2}$ removal mechanisms other than ventilation, such as air cleaning of $\mathrm{CO}_{2}$.

\section{Remaining Issues/Questions}

Is it economical for $\mathrm{CO}_{2}$-based DCV to be applied in mild climates even with an economizer?

While $\mathrm{CO}_{2}$-based DCV may not be cost-effective for most buildings with no heating demand in low humidity climates, $\mathrm{CO}_{2}$-based DCV may still be considered for potential IAQ benefits or ensuring 'adequate' ventilation. How significant are these IAQ benefits?

\section{$\underline{\mathrm{CO}}_{2} \underline{\text { DCV Technology }}$}

Most $\mathrm{CO}_{2}$ sensors used in DCV systems today are based on non-dispersive infrared (NDIR) or photometric detection. Both technologies can be affected by light source aging. The former approach may be sensitive to particle buildup on the sensor while the latter could be affected by vibration or atmospheric pressure changes. 


\section{Good sensor attributes and application}

Appropriate measurement ranges for ventilation control.

Calibrated according to manufacturer recommendations. An automated calibration system that uses overnight baseline $\mathrm{CO}_{2}$ readings may be considered.

Located in occupied zones when an appropriate location is available..

Poor sensor attributes and application

Should not use $\mathrm{CO}_{2}$ monitors that are not intended for control systems.

Should not be located near doors, windows, air intakes or exhausts, or in close proximity to occupants.

A single sensor located in a common return should not be used to control ventilation rates for spaces with very different expected occupancies.

\section{Remaining Issues/Questions}

Is it acceptable to use a single sensor in a common return to control the ventilation rate for multiple zones with similar expected occupancies? Can a lower setpoint compensate for differences in concentrations between zones? How much could this approach reduce energy savings?

Are there significant advantages to using a single sensor with multiple measurement locations compared to multiple sensors?

\section{Control Algorithms}

Control strategies for $\mathrm{CO}_{2}$-based DCV include simple setpoint control where the ventilation rate is increased or decreased depending on the indoor $\mathrm{CO}_{2}$ concentration, proportional control in which the ventilation rate is proportional to the $\mathrm{CO}_{2}$ concentration, PI (proportional-integral) or PID (proportional-integral-derivative) control which can adjust more quickly to changes in the $\mathrm{CO}_{2}$ concentration, and algorithms that aim to maintain a constant ventilation rate per person at all times.

\section{Good practice}

Control strategies should be chosen based on the expected occupancy patterns. Control algorithms that can adjust ventilation rates more quickly should be considered for spaces with low density occupancy or where changes in occupancy may be gradual .

\section{Remaining Issues/Questions}

Should $\mathrm{CO}_{2}$ setpoints be varied for buildings with occupants whose $\mathrm{CO}_{2}$ generation is expected to vary significantly from that of adults doing office work? It is necessary to account for the lower $\mathrm{CO}_{2}$ generation of children in schools or the higher generation of very active adults? Is a control algorithm that maintains a constant ventilation rate per person necessary for acceptable IAQ?

\section{$\underline{\text { Other Contaminants }}$}

$\mathrm{CO}_{2}$-based DCV systems should include a strategy to provide for sufficient ventilation, or other means, to control concentrations of non-occupant generated contaminants. Ideally, an analysis of non-occupant sources would indicate the appropriate ventilation and other IAQ control technologies needed to maintain the resulting concentrations of contaminants within acceptable limits. However, the information needed to perform such an analysis will not likely be available in most situations. 


\section{Good practice}

$\mathrm{CO}_{2}$-based DCV should include a strategy of ventilation and other IAQ control technologies to control non-occupant generated contaminants. It may be possible to control known pollutant sources through local ventilation or air cleaning.

\section{Poor practice}

$\mathrm{CO}_{2}$-based DCV may not be appropriate in spaces where smoking is permitted.

\section{Remaining Issues/Questions}

What level of minimum ventilation, if any, is needed? Although recommendations have been made to maintain a minimum ventilation rate of $10 \%$ to $50 \%$ of the design rate, no general rule of thumb is available. Minimum ventilation rates should be established based on expected types and strengths of pollutant sources, and other IAQ control technologies employed.

Can scheduled purges replace the minimum ventilation rate? It may be possible to maintain average contaminant concentrations below the same limits that would result from a constant ventilation rate by scheduling purges at appropriate times, such as prior to occupancy. Such a strategy may save energy if the purges can be scheduled in the afternoon during heating season and during the morning in the cooling season.

\section{Other Considerations}

The selection and design of a $\mathrm{CO}_{2}$-based DCV system cannot be viewed in isolation. The air quality and energy performance of a DCV system will impact and be impacted by other building and HVAC systems. While no comprehensive listing of potential interactions is available, significant interactions can occur with economizers, displacement ventilation, and other technologies.

\section{Good practice}

In buildings with an economizer cycle, the economizer should be allowed to override the DCV system at times when the additional ventilation would provide 'free' cooling.

Consider installation of an outdoor $\mathrm{CO}_{2}$ sensor if outdoor levels are expected to deviate significantly (more than about $20 \%$ ) from $720 \mathrm{mg} / \mathrm{m}^{3}$ (400 ppm(v)). The outdoor $\mathrm{CO}_{2}$ concentrations can be assumed to be $720 \mathrm{mg} / \mathrm{m}^{3}$ (400 ppm(v)) for most applications, but urban areas may have local effects resulting in higher levels. The higher outdoor level could result in overventilation and it may be economical to install an additional sensor to control the difference between indoor and outdoor concentration directly. Such an installation could also be required by applicable standards or codes.

\section{"Poor" practice}

$\mathrm{CO}_{2}$-based DCV may not be appropriate in buildings in mild climates (little or no heating demand and low humidity) unless an economizer is also used.

\section{Remaining Issues/Questions}

If a displacement ventilation system is used, where should the sensor be located and can the setpoint be lowered? 